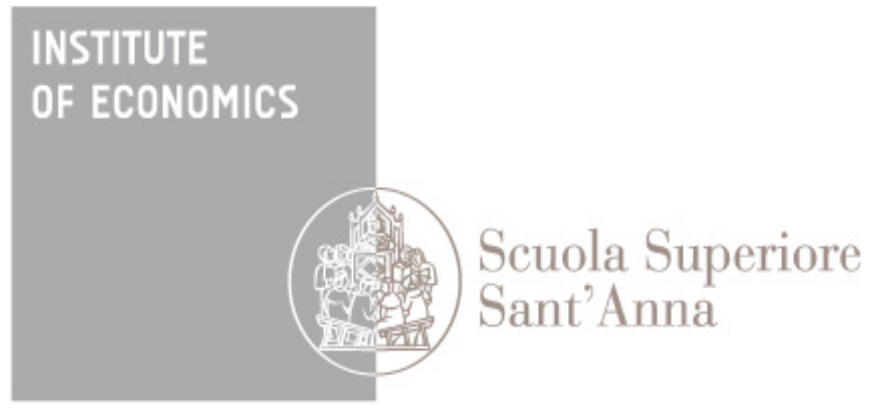

LEM | Laboratory of Economics and Management

Institute of Economics

Scuola Superiore Sant'Anna

Piazza Martiri della Libertà, 33 - 56127 Pisa, Italy ph. +3905088.33 .43$

institute.economics@sssup.it

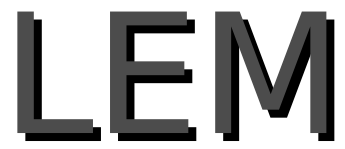

Working Paper Series

\title{
Concordance and Complementarity in IP Instruments
}

\author{
Marco Grazzi a \\ Chiara Piccardo ${ }^{b}$ \\ Cecilia Vergari ${ }^{c}$
}

${ }^{a}$ Department of Economic Policy, Università Cattolica del Sacro Cuore, Milan, Italy.

${ }^{b}$ Department of Economics, University of Verona, Italy.

${ }^{c}$ Department of Economics and Management, University of Pisa, Italy.

\section{9/19 June 2019}

ISSN(ONLINE) 2284-0400 


\title{
CONCORDANCE AND COMPLEMENTARITY IN IP INSTRUMENTS*
}

\author{
Marco Grazzi ${ }^{1}$, Chiara Piccardo ${ }^{2}$, and Cecilia Vergari ${ }^{3}$ \\ ${ }^{1}$ Department of Economic Policy, Università Cattolica del Sacro Cuore \\ ${ }^{2}$ Department of Economics, University of Verona \\ ${ }^{3}$ Department of Economics and Management, University of Pisa
}

June 13, 2019

\begin{abstract}
This work investigates the relationship between proxies of innovation activities, such as patents and trademarks, and firm performance in terms of revenues, growth and profitability. By resorting to the virtual universe of Italian manufacturing firms this work provides a rather complete picture of the Intellectual Property (IP) strategies pursued by Italian firms, in terms of patents and trademarks, and we study whether the two instruments for protecting IP exhibit complementarity or substitutability. In addition, and to our knowledge novel, we propose a measure of concordance (or proximity) between the patents and trademarks owned by the same firm and we then investigate whether such concordance exert any effect on performance.
\end{abstract}

Keywords: Trademarks, Patents, Innovation, Intellectual Property, Complementarity, Concordance, Technological proximity, firm performance, firm growth

\footnotetext{
*We thank the participants to the Department of Economics Unibo internal seminar (June 2018), the European Commission Joint Research Center seminar (JRC-Seville, June 2018), the European Association for Evolutionary Political Economy (EAEPE) conference (September 2018) and the IP Statistics for Decision Makers (IPSDM) conference in Alicante (October 2018). We are grateful to Roberto Susanna (Infocamere press office) and to Bureau van Dijk for their technical assistance at various stage. We are also indebted to Hanna Hottenrott, Laura Magazzini, Arianna Martinelli, Daniele Moschella, Gabriele Pellegrino, Emanuele Pugliese, Enrico Santarelli, Antonio Vezzani and Nikolas J. Zolas for insightful comments. All remaining errors are our own. This work received fundings by the Fondazione Cassa di Risparmio of Forlì, project ORGANIMPRE. This work has been partly supported by the European Commission under the H2020, GROWING PRO, GA no. 822781, WP1. @2019. This manuscript version is made available under the CC-BY-NC-ND 4.0 license
} 


\section{Introduction and related literature}

This work investigates the effect of patents and trademarks on firm performance. To do this, we employ the virtual universe of Italian limited liability manufacturing companies and we analyse their Intellectual Properties (IP) strategies. We then study whether the joint use of patents and trademarks exhibits complementarity or substitutability and, finally, we propose a novel measure to assess the concordance between the two instruments, when firms employ both.

The question of how innovation activity affects firms' performance has a long tradition in economics, with many recent contributions focusing on the analysis of $R \& D$ and patents, especially for large and medium firms. In particular, starting with Griliches (1981), many authors investigated the relationship between firm's market value and its $R \& D$ expenditures and number of patents, often focusing on large quoted companies (see e.g., Hall, 2000; Toivanen et al., 2002). Others, in addition to $R \& D$, analyse the impact of product and process innovation based on survey data (see e.g., among the many others, Hall et al., 2009).

A recent wave of studies, starting with Mendonça et al. (2004), has suggested that, on top of patents, trademarks provide a useful proxy for firms' innovation activity. This is even more true for small and medium enterprises, SMEs henceforth, and for 'softer' types of (non-patentable, non-technological) innovation like service, marketing and organizational innovations as well as innovation activities closer to the market introduction stage (see e.g., Flikkema et al., 2014; Helmers and Rogers, 2010; Flikkema et al., 2019). Indeed, for instance, SMEs may not be in the position of affording other protection mechanisms, see for instance Block et al. (2015). Moreover, while patents have a finite duration, trademarks do not expire as long as all post registration maintenance documents are timely filed. A trademark can thus protect a product (or service) when a similarly aged patent would expire. Schautschick and Greenhalgh (2016) provide a detailed survey of the empirical works revealing significant correlations between innovation, patents and trademarks and testing for the suitability of trademarks as proxy for innovation.

In line with this recent strand of literature, we study how and to what extent, innovation activities, as proxied by patents and trademarks, affect firms' performance in terms of revenues, growth and profitability. We consider balance-sheet data matched with IP activity of the (virtual) universe of Italian manufacturing limited liability firms, independently of their size. This feature of the dataset allows us to contribute to the literature in several directions. First, we can provide a complete picture of patent and trademark activities of Italian firms and assess whether, for instance, there exists a size or sectorspecific pattern. Second, we can dig into the effects of these innovation proxies, not only on large firms (as investigated, among others, by Castaldi and Dosso, 2018) but also on small and medium firms. Note that this is quite relevant as SMEs, which represent the vast majority of Italian firms, are more likely to resort to trademarks over patents, relative to large firms. Moreover, we investigate whether there is some complementarity or substitutability among the two IP instruments. Finally, and to our knowledge completely novel, for firms reporting both patents and trademarks, we employ the available information to build a measure of concordance (or proximity) between the stocks of patents and trademarks owned by the same firm and we then investigate whether such concordance may have an impact on performance. Notice that our approach, although different, bears some complementarity with that proposed in Flikkema et al. (2019) where trademarks are shown to be related to product innovation and, even more so, for manufacturing firms. 
The direction we start to explore here is made available by the contemporaneous availability of firm level IP data and recent developments in Algorithmic Links with Probabilities (ALP) (see, among the others, Lybbert and Zolas, 2014). Although not perfect, the linkages established between patents and trademarks thanks to ALP enables to investigate a number of issues. In this respect, with the limitations just recalled, our work provides an analytical tool to relate trademarks to innovation, in our case proxied by patents. The framework we propose also allows to assess the relative timing in the activities of patenting and trademarking and the impact of the concordance measure on firm performance. In this respect, our prior, in line with the capability view of the firm, is that a higher concordance or overlap between the pool of knowledge, as proxied by patents, and the set of products sold, as proxied by trademarks, should be associated to better firm performance (see among the many others Teece et al., 1994; Markides and Williamson, 1996; Bryce and Winter, 2009).

Our findings reveal that both patents and trademarks do have a role in explaining firm performance, in terms of revenues, growth and profitability. In particular, firms' with both IP rights enjoy a higher premium than firms only owning either patents or trademarks. Moreover, our findings suggest that the positive impact of having only trademarks is somewhat larger than the positive impact of owning patents alone. The data at our disposal do not allow to explore this result at greater detail, however we might conjecture that this is related to the very nature of trademarks as 'recognisable designations and symbols for goods and services' (Mendonça et al., 2004) hence playing a more crucial role in the process of marketing innovation vis à vis patents. Further, trademarks are the most diffused instrument of IP protection for Italian firms. We have to notice however that when focusing on the degree of concordance between the stock of patents and trademarks, one faces the constraint, particularly binding for the Italian case, of restricting the sample to firms owning both IP instruments.

As said, following the seminal work of Mendonça et al. (2004), a number of contributions have focused on trademarks as an appropriate indicator of innovation output, in addition to the more standard proxy traditionally provided by patents. Due to data constraints, most of these works focus on large and medium firms that are publicly traded and find evidence of a positive effect of trademarks on firms' stock market value (see e.g., Greenhalgh and Rogers, 2006, 2012).

Interestingly, Llerena and Millot (2013) examine the separate and combined effects of patents and trademarks on the market value of a sample of French quoted companies. They develop a theoretical model and, based on super-modularity theory, they test whether the two types of IP are complementary or substitute. In line with their theoretical predictions, they find that results differ across sectors. In chemical and pharmaceutical industries, patents and trademarks tend to be complementary whereas in high-tech business sectors, where the crucial asset to be protected is the technology rather than the brand, they are found to be substitutes.

In general, there are few contributions encompassing also small and medium firms. An exception is Rogers et al. (2007) that cover UK small and medium firms over the period 2001-2004. They study the effect of the registration of a new trademark over the following years and find that, because of the investment needed to launch an innovation, the profits may initially decrease even when the new product is ultimately successful. In comparison with the other companies, trademark active firms are more concentrated in the lowest and highest quartiles of the profits distribution.

The rest of the paper is organized as follows. The description of the data and the 
definition of the variables of interest is reported in Section 2. We next present some nonparametric evidence based on univariate kernel density estimations and on the FlignerPolicello test of stochastic equality in Section 4. Section 5 illustrates our empirical strategy and discusses the empirical results. Section 6 concludes.

\section{Data and variables of interest}

The empirical analysis is based on AIDA (Analisi Informatizzata delle Aziende) and AMADEUS data, two datasets provided by Bureau van Dijk (BvD).

The AIDA dataset provides detailed information on Italian limited liability companies operating in both the manufacturing and service sectors which, in accordance to law, have to deposit their balance sheets to the Chamber of Commerce. The data provide financial and economic information for Italian firms, as well as a wide set of relevant indicators, including number of employees, incorporation year and sector of activity, among others. ${ }^{1}$

The AIDA dataset, due to its nature, covers virtually the universe of Italian limited liability firms independently of their size or age, thus representing an ideal set of data to study the dynamics of firms and industries. This is a noteworthy feature with respect to many previous works (see Fang et al. (2011), Chang et al. (2012), Dernis et al. (2015), Daiko et al. (2017) and Dosso and Vezzani (2017), among others) that, due to data constraints, could only focus on top corporate R\&D investors or on firms operating in high-tech industries. The time period covered by our empirical analysis spans from 2006 to 2014 and we focus primarily on manufacturing firms, although we verify whether similar results also hold for service firs. ${ }^{2}$

We integrate AIDA data with information on the stock of applied patents ${ }^{3}$ and registered trademarks owned by firms in each relevant year. As for patents, AMADEUS provides some relevant information, including international patent classification (IPC), the application date and whether a patent has been granted or not, among others; while, for filed trademarks one can resort to NICE classification code, the filing date and information on their registration. In particular, information on the patents and trademarks classifications (IPC and NICE, respectively) are crucial in order to define a measure of economic concordance between the technological fields of the two measures of IP rights.

Before proceeding with some descriptive statistics on the dataset, we illustrate the strategy adopted to characterize firms' innovation activity and the degree of concordance between the domains of knowledge incorporated in the firms' stocks of patents and trademarks, respectively.

\footnotetext{
${ }^{1}$ We use two AIDA 'historic' disks in the release version of December 2015 and December 2016, respectively. For a detailed description of the procedures followed in building the dataset, refer to Grazzi et al. (2018).

${ }^{2}$ As suggested by the previous literature, see OHIM (2015); Schautschick and Greenhalgh (2016); Graham et al. (2018) among others, patenting activity is mainly observed within manufacturing sectors, while trademarks are of more widespread use independently of the sector of activity. Consistent evidence emerge using the AIDA-AMADEUS dataset in this work. However, in Section 5.2, we replicate our main analysis for firms in service sector, in order to check for potential differences.

${ }^{3}$ We have opted to focus on applied, rather than granted patents, to enlarge as much as possible the sample of observations, given the very small percentage of Italian firms with patents. Results on the smaller sample (granted patents) are also available upon request.
} 


\subsection{Patents, trademarks and a measure of IP instruments con- cordance}

In order to obtain a suitable measure of firms' innovation activities as proxied by patents, we consider data on applied patents, irrespectively of the outcome of the application, that have been applied at the United States Patent and Trademark Office (USPTO), at the European Patent Office (EPO), and/or at the Italian Patent and Trademark Office (IPTO). ${ }^{4}$ The stock of patents for each firm, in each year, does not include patents applied more than 20 years before the year of interest. That is, if a patent was applied in 1991 by a firm, we include it in the patent count from 2006 to 2010, but not from 2011 onward. This choice allows us to forego patents which are too 'old' to adequately represent a valuable proxy of firms' technological capabilities. ${ }^{5}$ Note that the range of information on patents accessible through BvD is only a subset of what available through PATSTAT, see for instance De Rassenfosse et al. (2014). Also note that, as shown in Table 1, only a very small fraction of Italian firms, around $7 \%$, holds patents, see also Malerba and Orsenigo (1999), Cefis and Orsenigo (2001) and the more recent Dosi et al. (2015). One known issue of the literature on IP is the matching to firm-level data. In this respect, note that we are employing patents and trademarks linked to firms as originally provided in BvD AMADEUS. ${ }^{6}$

With regard to trademarks, we focus on registered trademarks that have been filed at the United States Patent and Trademark Office (USPTO) or at the European Union Intellectual Property Office (EUIPO), formerly known as Office for Harmonization in the Internal Market (OHIM). ${ }^{7}$ We identify the stock of registered trademarks for each firm, in each year, by considering trademarks applied before or in the year of interest and expiring after the year of analysis. Unfortunately, differently from patents, AMADEUS does not provide information for registered trademarks also at national level. ${ }^{8}$

\footnotetext{
${ }^{4}$ Patents could be owned by more than one firm; in these cases we associated the patents to each owner, as suggested by the existing literature.

${ }^{5}$ Czarnitzki and Kraft (2004), Xu and Chiang (2005), Belderbos et al. (2014) and de Rassenfosse and Jaffe (2018), among others, have highlighted the importance to account for the decline in patents' value during the life of patented inventions. Our choice to censor the stock of patents for each firm, in each year, at 20 years is in line with the application of a constant $15 \%$ depreciation rate (that is commonly used in the literature in order to discount R\&D, patent and trademark values).

${ }^{6}$ An alternative attempt is provided, still on Italian firms, by Lotti and Marin (2013) on EPO applications which the authors match to a restricted sample of AIDA firms (the so called, BvD AIDA TOP). In the end, their effort results in 5485 patenting firms over the period 2000-2007. It is however not possible to directly compare the two final datasets. It is true that our displays a higher number of firms with patents (8616 in 2006, see Table 1), but this is most likely due to employing the "full" AIDA version and, although to a lesser extent, to counting USPTO and IPTO patent applications.

${ }^{7}$ As for patents, also trademarks can be jointly owned by more than one firm; in these cases we associated the trademarks to each owner, as suggested by the existing literature. Note however that the phenomenon of joint trademark ownership is much more limited with respect to patents.

${ }^{8}$ The lack of applications for trademarks at the national level is of course expected to reduce both the overall stock of trademarks in the country as well as the share of firms holding trademarks. It is however very difficult to find a reference to assess how large is the actual impact on our dataset. To the best of our knowledge, OHIM (2015) provides some guidance in terms of aggregate statistics even if it is at the EU level with no possibility to distinguish among countries. According to Table 8 (page 40) of the cited document, "38.1 per cent of all large companies and 8.6 per cent of all SMEs own trademarks", either at national or EU. In our dataset, which includes USPTO and EUIPO trademarks, the corresponding percentages are respectively (see Table 2$) 57.9 \approx(679 / 1172)$ and $12.4 \approx(3805+2653) /(44148+8016)$. Hence, it would not appear that the lack of national trademarks greatly compromises the sample that we employ.
} 
Before proceeding let us also notice that the results that we present in the following are robust to marginal adjustments such as considering a shorter lifetime for both patents and trademarks or applying some discounting factor to patents.

We next define, at the firm level, a variable to measure the degree of concordance between the two classes of IP instruments, patents and trademarks. For this purpose, we need information on IPC codes associated to each patent and NICE code linked to each trademark. ${ }^{9}$ In the AMADEUS dataset, a single patent can be associated with more than one IPC code, while for trademarks only a single NICE code is provided.

In order to build such concordance measure, we rely on a series of crosswalks linking different classifications of industries, products, IPC and NICE codes, for which we refer to the works of Lybbert and Zolas (2014), Zolas et al. (2017) and Goldschlag et al. (2016). As a preliminary step, we need to convert the IPC codes and the NICE codes to a common code. In particular, we associate the International Standard Industrial Classification (ISIC) to each IPC and to each NICE code, respectively, relying on the probabilistic algorithms developed by Lybbert and Zolas (2014) and Zolas et al. (2017). These algorithms provide a concordance of each IPC and NICE code to ISIC codes. Namely, for each 3-digit IPC code several 2-digit ISIC codes may be associated, each with a weight that identifies the likelihood (or strength) of the linkage between that particular IPC code and that particular ISIC code. The sum of these weights is one. Similarly, each 2-digit NICE code is associated to several 2-digit ISIC codes, each with a weight that represents the probability of concordance between that particular NICE code and that particular ISIC code. The sum of these weights is then one.

We obtain the concordance measure between patents and trademarks following a three-step procedure. Note that this measure is provided for any firm with patents and trademarks and it might vary over time. First, for each firm $(i)$ and year $(t)$, we identify the sets of 3-digit IPC and 2-digit NICE codes associated to the stock of patents and trademarks, respectively, and we label $N_{L}^{i, t}\left(N_{K}^{i, t}\right)$ the number of IPC (NICE) codes associated to these sets. ${ }^{10}$ In the second step, considering the ISIC codes and their probability weights, ${ }^{11}$ we compute the overlapping coefficient, overlap ${ }_{L-K}$, for each pair $(L, K)$ of IPC and NICE codes. ${ }^{12}$ Formally:

$$
\operatorname{overlap}_{L-K}=\sum_{j=1}^{N_{L K}} \min \left\{p_{L}\left(i s i c_{j}\right), p_{K}\left(i s i c_{j}\right)\right\},
$$

where $N_{L K}$ is the number of ISIC codes associated to each pair of 3-digit IPC and 2-digit NICE codes, $p_{L}\left(i s i c_{j}\right)$ is the probability weight that identifies the likelihood of the linkage between IPC code $L$ and ISIC code $j$, and $p_{K}\left(i s i c_{j}\right)$ is the likelihood of the linkage between NICE code $K$ and ISIC code $j$. The overlapping coefficient is higher than zero only when both the IPC and NICE codes are linked to at least one common ISIC code. Indeed, the

\footnotetext{
${ }^{9}$ The IPC is a classification for patents and utility models according to the different areas of technology to which they pertain. We use it at the 3-digit level. NICE is a 2-digit international classification of goods (codes from 1 to 34) and services (codes from 35 to 45) applied for the registration of trademarks that has been adopted with the Nice Agreement (1957).

${ }^{10}$ Clearly, we do not account for patents and trademarks without information on the IPC and NICE codes.

${ }^{11}$ For the methodology and weights refer to works of Lybbert and Zolas (2014), Zolas et al. (2017) and Goldschlag et al. (2016).

${ }^{12}$ The overlapping coefficient is a measure of agreement (or similarity) which refers to the area under two probability density functions simultaneously. Notice that the overlapping coefficient between an IPC and a NICE code is not firm or time specific.
} 
probability weights in equation (1) are both positive only when an ISIC code is associated to both IPC and NICE codes. Contrarily, if an ISIC code is not linked to either IPC or NICE code, the probability weight is set equal to zero. In the third and final step, we compute, for each firm and year, the degree of concordance between (the stock of IPC and NICE codes associated to) the stock of patents and trademarks. In particular, as shown in equation (2), for each firm $(i)$ in each year $(t)$, we sum all the overlapping coefficients identified for each pair of IPC $(L)$ and NICE $(K)$ codes (overlap ${ }_{L-K}$ ). Moreover, we normalize our measure dividing it by the product between the number of elements in the set of 3-digit IPC codes $\left(N_{L}^{i, t}\right)$ and the number of elements in the set of 2-digit NICE codes $\left(N_{K}^{i, t}\right)$.

$$
\operatorname{conc}_{i, t}=\left(\sum_{L=1}^{N_{L}^{i, t}} \sum_{K=1}^{N_{K}^{i, t}} \text { overlap }_{L-K}\right) /\left(N_{L}^{i, t} * N_{K}^{i, t}\right)
$$

The degree of concordance takes value zero if there are no common ISIC codes associated to the two sets of IPC and NICE codes, while strictly positive and higher values of conc $_{i, t}$ suggest higher concordance between the stocks of patents and trademarks. Notice that the measure we are proposing captures the degree of concordance between the stock of unique IPC and NICE codes associated to the stock of patents and trademarks of the firm. Accounting for unique IPC also enables to insulate against the existence of patents related to the same innovation (patent families) that cannot be identified in our data.

Let us describe in a nutshell how the procedure actually works. Consider as an example a firm with one patent and one trademark. We exploit the crosswalk from IPC to ISIC codes (and we get a set, say A, of ISIC codes associated to the set of IPC codes of the unique patent). Analogously, we map NICE to ISIC codes (and we get a set, say $\mathrm{B}$ of ISIC codes associated to the set of NICE codes of its unique trademark), and then we analyse to which extent these two sets of ISIC codes (A and B) overlap. Suppose that these two IP rights are characterized by IPC and NICE codes that map in the same ISIC codes (suppose also with the same weights), so that sets A and B perfectly overlap and we would get a measure of concordance equal to one $\left(\operatorname{conc}_{i, t}=1\right) .{ }^{13}$ For illustrative purposes, in Appendix 7, we provide an example from our database on how to construct this measure. ${ }^{14}$

\section{Descriptive statistics}

We next present some of the main highlights of the dataset that will be employed in the empirical analysis.

\footnotetext{
${ }^{13}$ Alternative procedures such as mapping IPC to ISIC codes and then ISIC to NICE codes of the firm (or, vice versa going from NICE to ISIC codes and then from ISIC to IPC codes) would of course be possible, but they would complicate the analysis and would underestimate the concordance measure as they would imply going through double weighting.

${ }^{14}$ Note that, as common to empirical investigations with firm level data, our measure is potentially sensitive to relevant events affecting the life-cycle of a firm such as mergers and acquisitions. Consider two firms characterized by the maximal degree of concordance: each of them has only patents in technological fields perfectly related with its products (trademarks). Clearly, if these two firms merge, and their sets of IPC and NICE codes do not coincide, the degree of concordance of the new firm decreases. Of course this issue is related to the impossibility to appropriately deal with such events in standard firm level data.
} 
Table 1: Number of firms, trademarks and patents

\begin{tabular}{|c|c|c|c|c|c|c|c|}
\hline Year & Firms & $\begin{array}{c}\text { Firms } \\
\text { with } \\
\text { tm }(\%) *\end{array}$ & $\begin{array}{c}\text { Firms } \\
\text { with } \\
\text { pat }(\%) *\end{array}$ & $\begin{array}{c}\text { Firms } \\
\text { with } \\
\text { tm and pat } \\
(\%) *\end{array}$ & $\begin{array}{c}\text { Firms } \\
\text { with } \\
\text { conc }_{i, t}>0 \\
(\%) * *\end{array}$ & $\begin{array}{l}\text { Num } \\
\text { of } \\
\text { tm }\end{array}$ & $\begin{array}{l}\text { Num } \\
\text { of } \\
\text { pat }\end{array}$ \\
\hline 2006 & 116507 & $\begin{array}{r}4732 \\
(4.062)\end{array}$ & $\begin{array}{r}8616 \\
(7.359)\end{array}$ & $\begin{array}{r}1798 \\
(1.543)\end{array}$ & $\begin{array}{r}1623 \\
(90.267)\end{array}$ & 13190 & 77312 \\
\hline 2007 & 123007 & $\begin{array}{r}5340 \\
(4.341)\end{array}$ & $\begin{array}{r}8884 \\
(7.222)\end{array}$ & $\begin{array}{r}2018 \\
(1.641)\end{array}$ & $\begin{array}{r}1822 \\
(90.287)\end{array}$ & 15582 & 82797 \\
\hline 2008 & 129334 & $\begin{array}{r}6040 \\
(4.670)\end{array}$ & $\begin{array}{r}9100 \\
(7.036)\end{array}$ & $\begin{array}{r}2237 \\
(1.730)\end{array}$ & $\begin{array}{r}2013 \\
(89.987)\end{array}$ & 18508 & 87536 \\
\hline 2009 & 135091 & $\begin{array}{r}6679 \\
(4.944)\end{array}$ & $\begin{array}{r}9261 \\
(6.855)\end{array}$ & $\begin{array}{r}2389 \\
(1.768)\end{array}$ & $\begin{array}{r}2147 \\
(89.870)\end{array}$ & 21243 & 91482 \\
\hline 2010 & 141070 & $\begin{array}{r}7396 \\
(5.243)\end{array}$ & $\begin{array}{r}9506 \\
(6.738)\end{array}$ & $\begin{array}{r}2601 \\
(1.844)\end{array}$ & $\begin{array}{r}2347 \\
(90.235)\end{array}$ & 24442 & 95635 \\
\hline 2011 & 138641 & $\begin{array}{r}8011 \\
(5.778)\end{array}$ & $\begin{array}{r}9591 \\
(6.918)\end{array}$ & $\begin{array}{r}2772 \\
(1.999)\end{array}$ & $\begin{array}{r}2499 \\
(90.152)\end{array}$ & 27485 & 99510 \\
\hline 2012 & 135299 & $\begin{array}{r}8616 \\
(6.368)\end{array}$ & $\begin{array}{r}9419 \\
(6.962)\end{array}$ & $\begin{array}{r}2891 \\
(2.137)\end{array}$ & $\begin{array}{r}2606 \\
(90.142)\end{array}$ & 30384 & 101552 \\
\hline 2013 & 132731 & $\begin{array}{r}9070 \\
(6.833)\end{array}$ & $\begin{array}{r}9062 \\
(6.827)\end{array}$ & $\begin{array}{r}2927 \\
(2.205)\end{array}$ & $\begin{array}{r}2644 \\
(90.331)\end{array}$ & 32612 & 98872 \\
\hline 2014 & 129253 & $\begin{array}{r}8863 \\
(6.857)\end{array}$ & $\begin{array}{r}8608 \\
(6.660)\end{array}$ & $\begin{array}{r}2830 \\
(2.190)\end{array}$ & $\begin{array}{r}2556 \\
(90.318)\end{array}$ & 31740 & 93229 \\
\hline
\end{tabular}

Notes. We only consider firms operating in manufacturing sectors (we exclude firms operating in the following 2-digit ATECO 2007 code: 12 and 33).

* In brackets, percentage of total firms.

* * In brackets, as a percentage of firms with trademarks and patents.

\subsection{Distribution of patents and trademarks}

Table 1 reports the distribution of trademarks and patents for firms in the manufacturing sector. As expected on the basis of prior literature, the fraction of Italian firms owning IP instruments is very small and it displays different trends for patents and trademarks. Note indeed that the proportion of firms owning at least one registered trademark increases during the period of investigation (from $4.062 \%$ of firms in 2006 to $6.857 \%$ in 2014); while it is not the same for the fraction of firms owning at least one patent (it is around $7 \%$ in each year). ${ }^{15}$

Quite interestingly, in more recent years, the number of firms with trademarks exceeds the number of firms with patents. This points to the increasing importance of trademarks as instrument to protect IP, at least among Italian firms. However, also note, as shown by the last two columns of Table 1, that the total number of patents of Italian firms, even if decreasing in more recent years, is still bigger than the number of trademarks. ${ }^{16}$ Thus we can conclude that, at least in Italy, ownership of patents, differently from trademarks, is concentrated in a narrower set of companies and that trademarks are becoming more diffused as instrument of IP protection. As suggested in Hall et al. (2013), the concentration of patent ownership might be related to the fact that '(a) some firms do not automatically patent all of their patentable inventions, (b) some firms avoid the patent system altogether, either because of its cost or because patenting is perceived to yield no

\footnotetext{
${ }^{15}$ Such similar percentages of firms with patents and firms with trademarks might also be related to the absence of IPTO trademarks.

${ }^{16} \mathrm{~A}$ similar trend in the number of patents has been reported also by the Italian Observatory for patents, Osservatorio Italiano Brevetti, Osservatorio Italiano Brevetti (2014). Considering patents applied at the Italian Patent and Trademark Office (IPTO) from both Italian and foreign firms, the Observatory highlights a reduction in the number of applied patents starting from 2011.
} 


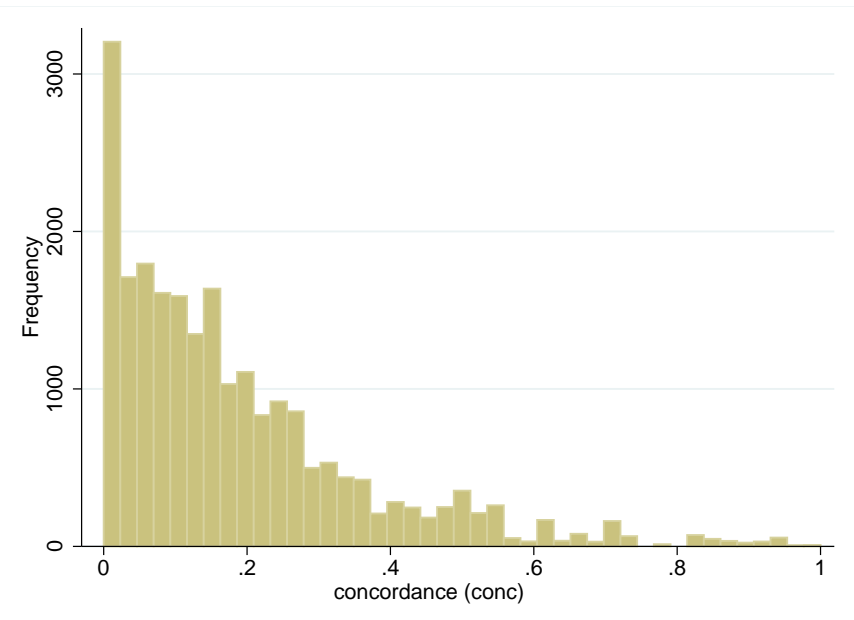

Figure 1: Distribution of the measure of IP concordance

additional benefit, and (c) some innovations involve inventions that are not patentable.' And, in addition, to the fact that there appears to be size threshold below which firms find it more difficult to afford the cost related to the functioning of a formal R\&D laboratory. Moreover, the data reveal that around $7 \%$ of firms with patents are involved in co-ownership (co-patents) and the number of the co-owned patents has increased over the years (the share of patents with more than one owner rises from $2.694 \%$ in 2006 to $3.145 \%$ in 2014). ${ }^{17}$

Note that due to the small number of firms owning IP rights in general, when we restrict to the sub-sample of firms with both patents and trademarks, we are left only with around $2 \%$ of the firms making up the original dataset, column (5) of Table 1 . The share of firms owning both patents and trademarks slightly increases over time, from $1.543 \%$ in 2006 to $2.190 \%$ in 2014. Focusing on the concordance between IP instruments, around $90 \%$ of firms reporting both patents and trademarks, column (6) of Table 1, displays a strictly positive value for the degree of concordance, conc $_{i, t}$, as defined in equation (2). Among these firms the average degree of concordance is around 0.18. The whole distribution is plotted in Figure 1 and it does not vary much over time because, at the firm level, the value of the concordance measure is quite stable over the years. In turn, this is due to the poor dynamics in patenting and trademarking, that is, very few firms are registering or applying for new trademarks or patents over the time span covered by the database; hence also the measure does not change much over time. Unfortunately, the co-occurrence of a very low number of firms with both IP and a poor underlying dynamics do not make the 'Italian case' the ideal test-bed for the measure we are proposing here. Finally, note that the proposed concordance measure, at least for the sample under investigation, appears to be independent from the size of the firm, see Figure 2.

\footnotetext{
${ }^{17}$ In the interest of space, we do not show descriptive statistics considering co-ownership of patents. They are available upon request.
} 


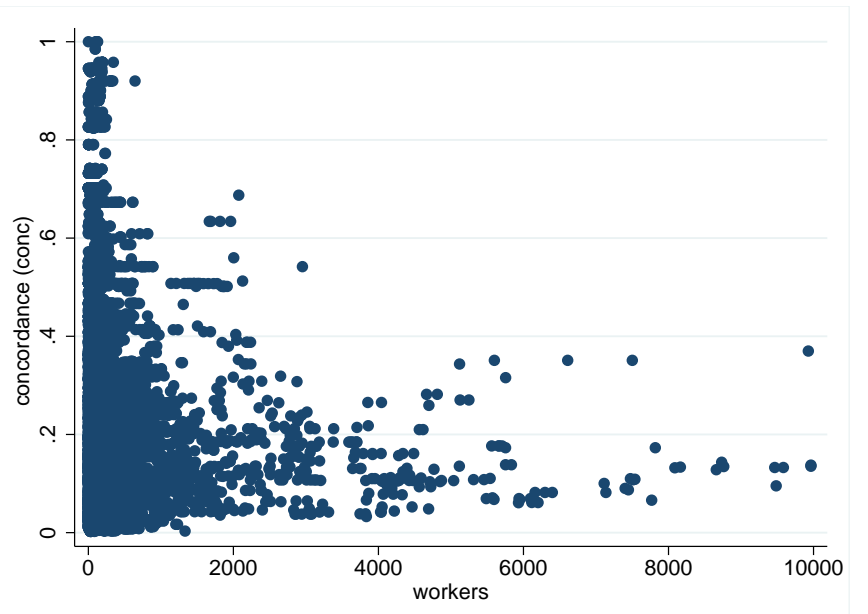

Figure 2: Firm size (number of workers) and concordance measure (strictly positive values)

\subsection{Distribution of patents and trademarks according to firm size and sector}

Table 2 shows the distribution of patents and trademarks across firms according to their size in 2014. The size classes are defined conforming to the Eurostat definition. ${ }^{18} \mathrm{We}$ consider four size classes: 'micro' firms with less than 10 workers; 'small' with workers ranging between 10 and 49; 'medium' between 50 and 249 and 'large' with more than 250 workers. ${ }^{19}$

Consistently with the actual population of Italian firms, also in our dataset the highest share of firms is represented by micro-firms (around 58\%). The share of small firms is around $35 \%$, while large firms are only less than $1 \%$. Due to the shape of the firm size distribution, in absolute numbers, the two categories of SMEs are those more represented in terms of IP's holders, and represent the highest share of firms with concordant patents and trademarks (around $32 \%$ and $43 \%$ of firms with concordant IP rights, respectively). Note however that, in relative terms, while around $55 \%(645 / 1172)$ of large firms are patent holders, the relative share shrinks respectively to $30 \%$ for medium and to $8.6 \%$ for small firms.

Looking at the number of patents and trademarks we note that the largest number of trademarks falls in the medium class (around 35\% of the total number of trademarks), while the highest share of patents is owned by large firms (around $42 \%$ of the total). In this respect, the descriptive evidence for Italy confirms the findings from previous studies highlighting a higher propensity to patent for large firms and identify trademarks as the main IP instrument for small and medium firms (see Mendonça et al. (2004), Blind et al. (2006), Leiponen and Byma (2009) and Flikkema et al. (2014) among others).

Finally, in the interest of space we do not report disaggregated statistics at the sector level, note however that trademarks are mostly concentrated in food products (ATECO

\footnotetext{
${ }^{18}$ The classification is available at: http://ec.europa.eu/eurostat/statistics-explained/index.php/Glossary:Enterprise_size

${ }^{19}$ Eurostat classification refers to the number of workers, thus including also the entrepreneur(s). AIDA dataset originally reports the number of employees and, as obvious, many SMEs report no employees. Hence, to make the two figures comparable, we approximate the number of workers as the number of employees plus one.
} 
Table 2: Number of firms, trademarks and patents for micro, small, medium and large firms. Year 2014

\begin{tabular}{lrrrrrrr}
\hline Size & Firms(\%)* & $\begin{array}{c}\text { Firms } \\
\text { with } \\
\text { tm(\%)* }\end{array}$ & $\begin{array}{c}\text { Firms } \\
\text { with } \\
\text { pat }(\%) *\end{array}$ & $\begin{array}{c}\text { Firms } \\
\text { with } \\
\text { tm and pat } \\
(\%) *\end{array}$ & $\begin{array}{c}\text { Firms } \\
\text { with } \\
\text { conc } \\
(\%, t>0\end{array}$ & $\begin{array}{c}\text { Num } \\
\text { of } \\
\text { tm } \\
(\%) * *\end{array}$ & $\begin{array}{c}\text { Num } \\
\text { of } \\
\text { pat } \\
(\%) * *\end{array}$ \\
\hline $0-9$ & 73641 & 1668 & 1673 & 223 & 187 & 3076 & 5910 \\
$10-49$ & $(57.996)$ & $(18.944)$ & $(19.556)$ & $(7.911)$ & $(7.345)$ & $(9.736)$ & $(6.366)$ \\
& 44148 & 3805 & 3805 & 933 & 805 & 9356 & 20141 \\
$50-249$ & $(34.769)$ & $(43.214)$ & $(44.477)$ & $(33.097)$ & $(31.618)$ & $(29.612)$ & $(21.695)$ \\
& 8016 & 2653 & 2432 & 1208 & 1114 & 11246 & 27599 \\
250 and more & $(6.313)$ & $(30.131)$ & $(28.428)$ & $(42.852)$ & $(43.755)$ & $(35.594)$ & $(29.728)$ \\
& 1172 & 679 & 645 & 455 & 440 & 7917 & 39187 \\
& $(0.923)$ & $(7.712)$ & $(7.539)$ & $(16.140)$ & $(17.282)$ & $(25.058)$ & $(42.211)$ \\
\hline
\end{tabular}

Notes. We only consider firms operating in manufacturing sectors (we exclude firms operating in the following 2-digit ATECO 2007 code: 12 and 33). The number of firms in this Table differ from the previous Table because 2276 firms do not have information on their size, measured in terms of workers, in 2014.

* In brackets, percentage of total firms, total firms with trademarks, patents, trademarks and patents, concordant trademarks and patents, respectively.

** In brackets, percentage of total number of trademarks and patents, respectively.

10, with around $14 \%$ of total number of trademarks), manufacture of machinery and equipment n.e.c. (ATECO 28, with around $11 \%$ of total number of trademarks), chemical products and wearing apparel (ATECO 20 and 14, both with around $8 \%$ of total number of trademarks). Sectors reporting the highest number of patents are manufacture of machinery and equipment n.e.c. (ATECO 28, with around $29 \%$ of total number of patents), manufacture of computer, electronic and optical products (ATECO 26, with around $13 \%$ of total number of patents) and manufacture of fabricated metal products, except machinery and equipment (ATECO 25, with around $11 \%$ of total number of patents).

\subsection{The timing of applications}

In addition to the analysis of IP bundles of firms and of their internal concordance, it is also much relevant to investigate if any regularity emerges in terms of the timing of applications for patents vis à vis trademarks. In this respect, our prior would be that in a given process of innovation, moving from the original concept, to the technological development of the product and finally to market introduction, the patent application, being more technology related, pre-dates the trademark application, which is more related to bringing the innovation to the market (see also the contribution of Mendonça et al., 2004; Aaker, 2007; Helmers and Rogers, 2010; Llerena and Millot, 2013; Flikkema et al., 2014). In our dataset, as in most to date, we cannot directly observe: a) which IP is related to a given product or line of business and, as a consequence, b) the timing with which firms resort to patents and trademarks along the innovation process. We can only indirectly infer the existence of such a sequential timing by exploiting positive occurrences of our concordance measure to identify innovation processes that we can expect to be related to the same product (or line of business). In particular, we consider, in each year and for each firm, the pairs of 3-digit IPC and 2-digit NICE codes associated to the stock of patents and trademarks, for which the overlapping coefficient is higher than zero, that is, when we are inclined to expect that the patent and the trademark are related to the same line of product. Moreover, for each pair of IPC and NICE codes, for each firm and year, we account for the least recent patent and trademark in the firm 
portfolio. Our descriptive evidence provides only mild support to our hypothesis on the relative timing: depending on the year of analysis, in $50 \%$ to $55 \%$ of such IPC-NICE pairs the patent pre-dates the trademark. ${ }^{20}$

\section{Non-parametric evidence}

\subsection{Comparison of the empirical distributions of firms' perfor- mance}

Before proceeding with more standard econometric analysis we report evidence from univariate kernel density estimations, which allows us to graphically compare the performance of different groups of firms.

We compare the empirical distributions of firms' performance across four groups of firms: without IP instruments, owning only trademarks, owning only patents and firms with both patents and trademarks. In the following, we will refer to the firms of the first group as non-innovative and to the rest as innovative firms. We warn the reader that this distinction is made for the sake of the exposition only. We are well aware that firms might opt for other modes to appropriate the returns associated to innovation. We proxy firms' performance by, alternatively, firms' total revenues in logs $\left(\ln \left(\right.\right.$ totre $\left.\left._{i, t}\right)\right)$, yearly growth rate $\left(\right.$ growt $\left._{i, t}\right)$, measured as the logarithmic difference between firms total revenues in two consecutive years, and profitability (ebitda_sales ${ }_{i, t}$ ). We measure profitability as the ratio between EBITDA and sales (multiplied by 100), where EBITDA stands for earnings before interest, taxes, depreciation and amortization. ${ }^{21}$ For the sake of completeness, we estimate kernel densities focusing on the first (2006) and last (2014) available years in the dataset, note however that there is not much intertemporal variation.

\section{Innovative vs. non innovative firms}

Graphically, we identify relevant differences between groups of firms in terms of total revenues. As reported in Figure 3, firms without any IP instrument underperform firms with patents and/or trademarks in terms of revenues. Among innovative firms, those with both patents and trademarks tend to show higher values in terms of total revenues; while firms owning only trademarks or only patents display similar distributions. In terms of profitability, Figure 5 displays that firms with IP rights outperform firms without patents and trademarks. On the contrary, these groups of firms do not seem to differ much in terms of growth rates, Figure 4. The only feature that is possible to appreciate from Figure 4 is the higher concentration around the mean for firms with both patents and trademarks, which might of course be related to the larger size (and smaller variance of growth rates) of firms with both IP.

The descriptive evidence on Italian firms is in line with the existing empirical literature, which reports higher performance for firms with IP instruments, even employing

\footnotetext{
${ }^{20}$ Dinlersoz et al. (2018) perform a similar exercise on the relative timing for R\&D, patents and trademark filings and report mild evidence in the opposite direction for US firms. Notice however that they do not employ any concordance measure.

${ }^{21}$ In order to mitigate problems related to measurement errors, we do not account for values of the profitability larger than 100 and lower than -300, the latter corresponding roughly to the bottom percentile of the distribution. In this way, over a total number of 1,180,933 observations for ebitda_sales, we remove around 15,000 observations.
} 


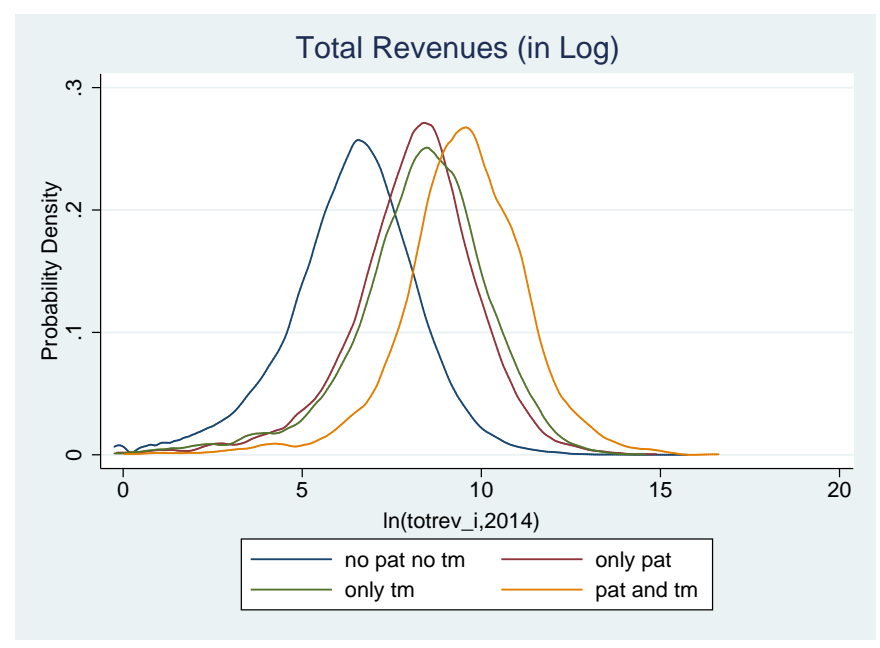

Figure 3: Empirical distribution of Total Revenues (in $\log$ ) in 2014, innovative vs noninnovative firms

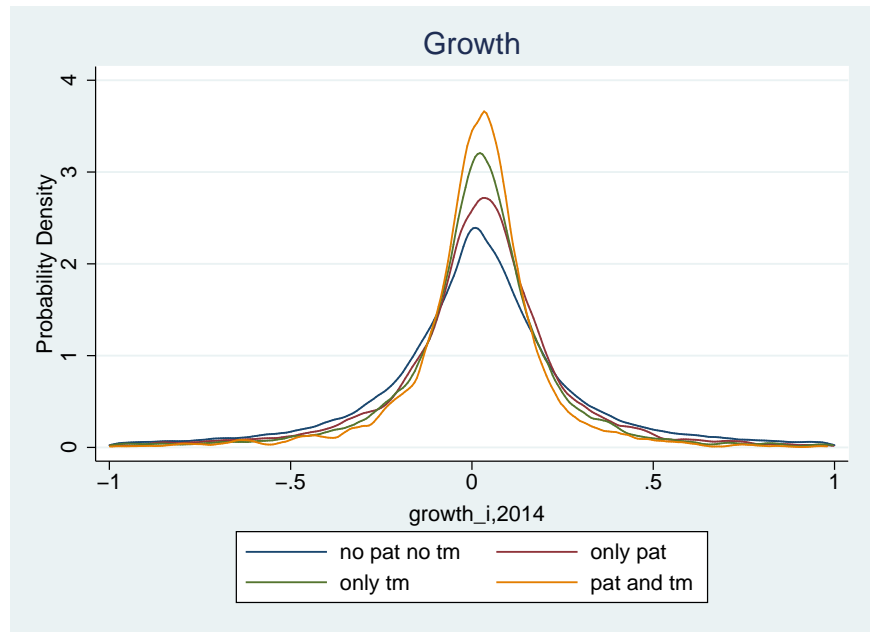

Figure 4: Empirical distribution of growth rates 2013-2014, innovative vs non-innovative firms

different measures of firm performance. In particular, given limited data availability on the universe, many contributions focus on market values of quoted companies or on specific sectors of the economy. Greenhalgh and Rogers (2012) and Sandner and Block (2011), among others, report a positive impact of both measures of IP on the markets' valuation of firms. Dosso and Vezzani (2017) and Llerena and Millot (2013) analyze and identify a positive influence of the combined use of patents and trademarks on firms' market value only for some industrial sectors. Graham and Somaya (2004), focusing on the software industry, also report evidence in favor of the complementarity hypothesis. Moreover, Zhou et al. (2016) identify a positive impact of the joint use of patents and trademarks on the start-up amount of venture capital funding. Other studies investigate the effect of patent and trademark activity on firms' survival and identify a positive correlation between these two measures of IP and a higher increase in the expected life span of firms (e.g., Jensen et al., 2008; Buddelmeyer et al., 2010; Helmers and Rogers, 2010; Wagner and Cockburn, 2010).

There is scant evidence on the relationship between IP instruments and firm growth. 


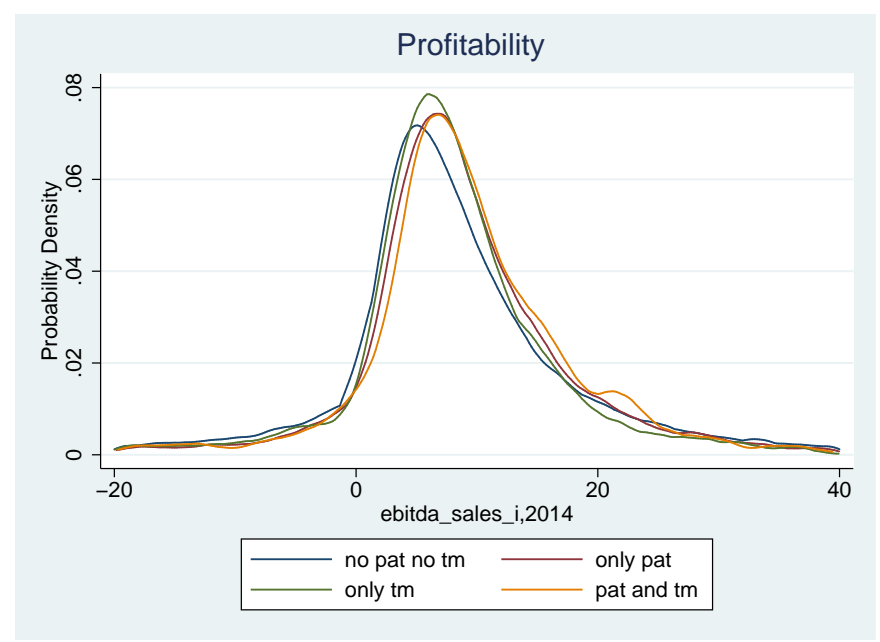

Figure 5: Empirical distribution of ebitda/sales in 2014, innovative vs non-innovative firms

In particular, Guzman and Stern (2015) show that both patent and trademark activities positively affect growth of a sample of start-ups in the Silicon Valley; however, authors do not focus on the potential combined impact of both trademarks and patents. More recently, Castaldi and Dosso (2018) analyze the effects of the combined impact of patents and trademarks on firm growth. They find that patents (as well as firms' R\&D stock) negatively affect firms' growth, although such negative impact is mitigated by the indirect positive effect of trademarks.

\section{Innovative firms: concordant vs. non-concordant IP rights}

We now focus our attention on the restricted sample of firms with both patents and trademarks, and we divide these firms into two groups according to whether their degree of concordance, conc $_{i, t}$ as defined in equation (2), is strictly positive (firms with concordant patents and trademarks) or nil. We graphically compare the distributions of these two groups. As exhibited in Figure 6, firms with concordant patents and trademarks mildly outperform those without concordant IP instruments in terms of total revenues. Contrarily, as shown in Figures 7 and 8, kernel density estimations do not show any difference in terms of growth and profitability for the two groups of firms. ${ }^{22}$

\subsection{Fligner-Policello test of stochastic equality}

To confer statistical accuracy to the graphical analysis reported above, we perform nonparametric Fligner-Policello (FP henceforth) test of stochastic equality, proposed by Fligner and Policello (1981) to compare innovative and non-innovative firms. As FP test allows to compare two groups at a time, we gather together firms with any proxy of innovative activity (firms owning only trademarks, only patents and both). The test is defined as follows. Let $F_{\mathrm{I}}$ and $F_{\mathrm{NI}}$ be the distributions of the relevant variables of innovative and non-innovative firms, respectively. Denote with $\mathrm{X}_{\mathrm{I}} \sim F_{\mathrm{I}}$ and $\mathrm{X}_{\mathrm{NI}} \sim F_{\mathrm{NI}}$ the associated

\footnotetext{
${ }^{22}$ Note that the non-parametric analysis only provides descriptive evidence. In order to take into consideration the size affect, we control for size in all the specifications included in the parametric analysis below.
} 


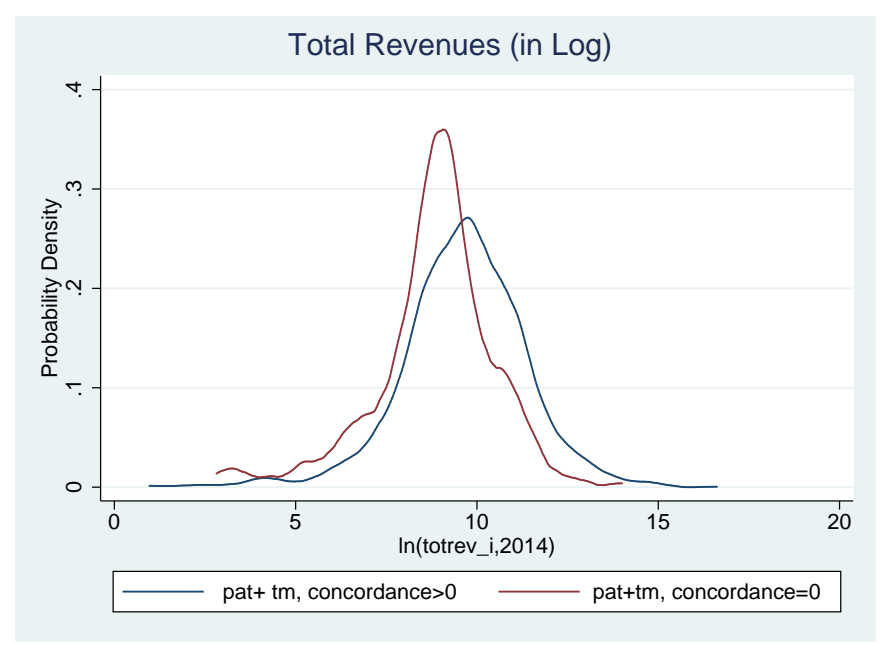

Figure 6: Empirical distribution of Total Revenues (in log) in 2014, concordant patents and trademarks vs non-concordant

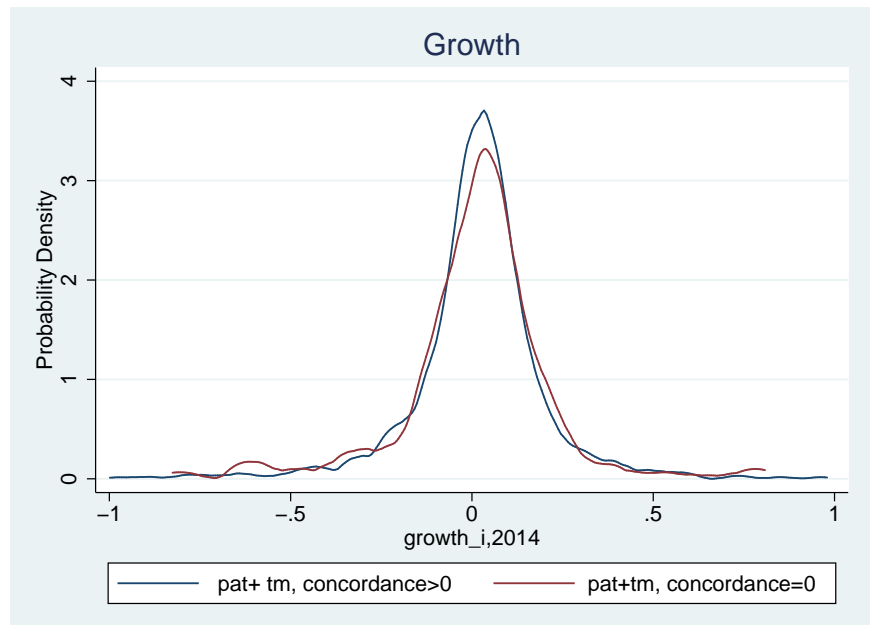

Figure 7: Empirical distribution of growth rates 2013-2014, concordant patents and trademarks vs non-concordant

random variables, and with $X_{\mathrm{I}}$ and $X_{\mathrm{NI}}$ two respective realizations. Based on the FP test, the distribution $F_{\mathrm{I}}$ is said to stochastically dominate $F_{\mathrm{NI}}$ if $\operatorname{Prob}\left\{X_{\mathrm{I}}>X_{\mathrm{NI}}\right\}>1 / 2 .{ }^{23}$

For each relevant variable (total revenues, growth and profitability) we compare, innovative with non-innovative firms in years 2006 and 2014, respectively. A positive sign of the FP statistic means that innovative firms have a higher likelihood to take on larger values of a given relevant variable (i.e. the distribution of innovative firms stochastically dominates the distribution of non-innovative firms), and the opposite holds if the statistic takes a negative sign. ${ }^{24}$

FP statistics show that innovative firms perform better with respect to non-innovative firms in terms of total revenues and profitability, while they do not appear to differ in terms of growth, in both years considered. FP statistics are thus confirming the descriptive evidence of the plots above.

Focusing on firms with both patents and trademarks, we perform the FP test in order

\footnotetext{
${ }^{23}$ The null hypothesis in the FP test implies equality of median among the compared distributions.

${ }^{24}$ In the interest of space we do not show the FP tests, but they are available upon request.
} 


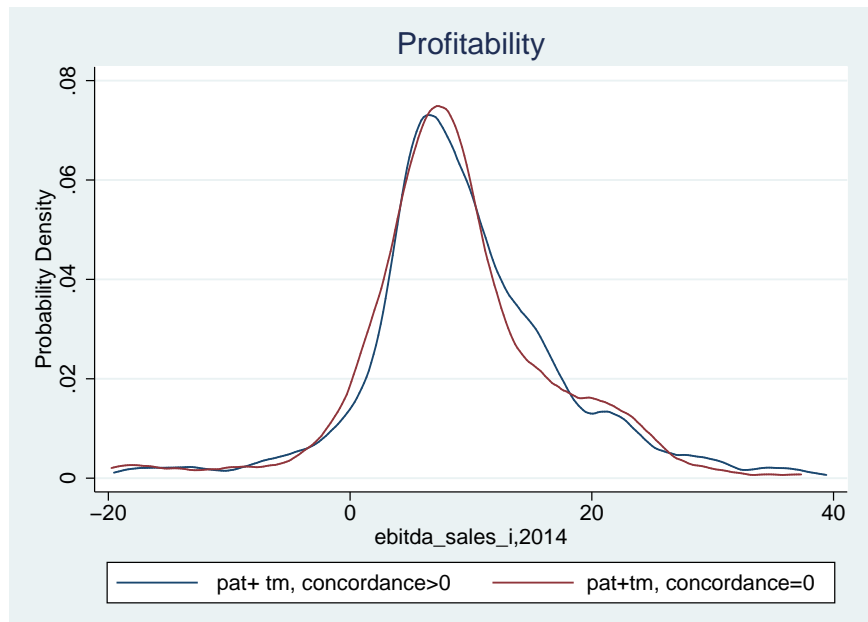

Figure 8: Empirical distribution of ebitda/sales in 2014, concordant patents and trademarks vs non-concordant

to compare performance between the two groups of firms with concordant IP instruments and firms without such concordance. Similarly to the graphical comparisons, firms with concordant IP instruments result to be characterized by higher total revenues. However, according to the FP test, concordance between IP instruments does not imply a relevant difference between firms in terms of growth and profitability.

\section{Parametric analysis of firms' performance}

In this section we investigate the effects of patents and trademarks on firms' performance resorting to parametric analysis. The dependent variable, $Y_{i, t}$, is firms' performance proxied by, alternatively, (the log of) firms' total revenues $\left(\ln \left(\right.\right.$ totre $\left.\left._{i, t}\right)\right)$, yearly growth rate $\left(\right.$ growth $\left._{i, t}\right)$, and profitability (ebitda_sales $\left.s_{i, t}\right)$.

We relate $Y_{i, t}$ to the innovation indicators and other controls through the following baseline specification:

$$
\begin{aligned}
Y_{i, t}= & \beta_{1} \text { nopattm }_{i, t-1}+\beta_{2} \text { tm }_{i, t-1}+\beta_{3} \text { pat }_{i, t-1}+\beta_{4} \text { both }_{i, t-1}+ \\
& \beta_{5} \ln \left(\text { workers }_{i, t-1}\right)+\beta_{6} \ln \left(L P_{i, t-1}\right)+X_{i, t}^{\prime} \alpha+u_{i, t}
\end{aligned}
$$

where $i$ denotes firms and $t$ years. The explanatory variables that we are mostly interested in consist of four dummy variables nopattm not $_{i, 1}, t m_{i, t-1}$, pat $_{i, t-1}$ and both $h_{i, t-1}$ equal to 1 if firms, respectively, do not own any IP right, own at least one registered trademark (but not patents), at least one (applied) patent (but not trademarks), both trademarks and patents. This is our preferred specification, as it is not affected by the presence of patent families that cannot be identified in the data. As put forth in previous works (see e.g., among others, Llerena and Millot, 2013; Cassiman and Veugelers, 2006), to ease the interpretation of coefficients, we include all the four exclusive IP strategy dummy indicators in the regressions, thus without the constant term. ${ }^{25}$ These dummy variables are mutually exclusive so that we can better identify the different IP strategies of the firms; at the same

\footnotetext{
${ }^{25}$ We build the four dummy variables based on the yearly number of patents and registered trademarks owned by firms. For more details on the construction of patents and trademarks stocks refer to Section 2.1 .
} 
time, we avoid problems of multicollinearity due to the high correlation between firms' trademarks and patents. Moreover, we include among independent variables firms' size, measured by the logarithmic transformation of the number of workers $\left(\ln \left(\right.\right.$ worker $\left.\left._{i, t-1}\right)\right)$ and the logarithmic transformation of labour productivity $\left(\ln \left(L P_{i, t-1}\right)\right){ }^{26}$ In order to reduce the potential endogeneity of our regressors, these variables are lagged one period with respect to the dependent variable. ${ }^{27}$ In the regression we account for a vector of controls, $X_{i, t}^{\prime}$, which includes: a set of 2-digit ATECO industry dummy variables; three geographical area dummy variables which identify firms operating in the North, Centre or South of Italy, respectively; and nine year dummies (2006-2014). These binary variables allow us to control for time invariant sectoral effects, for the omission of geographical specific time invariant characteristics which might bias our parameter estimates and, for the economic cycle and common macroeconomic factors, respectively. ${ }^{28}$

In order to assess whether the concordance between firms' stocks of patents and trademarks positively impact on firms' performance, in an extended specification, we also include the degree of concordance between IP rights, conc $_{i, t-1}$, as defined in equation (2), with a reporting lag of one year. Clearly, this specification only includes firms with both patents and trademarks. Hence, moving from the baseline specification to this extended one, the number of observations significantly decreases (from more than 600,000 to less than 18,000). In order to verify if results are driven by the lower number of observations, we also re-estimate the baseline specification on the sub-sample of firms with both patents and trademarks. ${ }^{29}$

We resort to Pooled OLS models for two reasons. First, given the rather poor dynamics in the patenting (trademarking) activities of Italian firms (i.e. firms are not registering or applying for many new trademarks or patents every year), for many companies the number of patents (trademarks) does not change over the period of observation, hence, for these firms, the effect of IP would get confounded with the firm fixed effect. Secondly, as shown by Angrist and Pischke (2008), estimating fully saturated dummy variables models with OLS is fully general, regardless of the distribution of the dependent variable.

Results, shown in Table 3, suggest that firms' innovative capacity is positively associated with performance. In particular, coherently with the non-parametric results, estimates show that patents and trademarks exert a positive impact on firms' total revenues, growth and profitability. More in detail, let $\beta_{1}, \beta_{2}, \beta_{3}$ and $\beta_{4}$ denote the coefficients of firms without IP rights, firms owning only trademarks, firms owning only patents and firms owning both patents and trademarks, respectively. the estimates report coefficients that are larger for the group of firms owning both IP instruments rather than either patents or trademarks. Our results suggest that having both patents and trademarks

\footnotetext{
${ }^{26}$ Labour productivity is computed as the ratio between added value and number of workers.

${ }^{27}$ In order to account for the potential endogeneity between labour productivity and the indicators for innovation activities, we have also estimated a structural model following the methodology originally proposed in Crepon et al. (1998). The results, which are quite reassuring, are not shown here in the interest of space, but are available upon request.

${ }^{28}$ Focusing on firms' growth as measure of performance, our regression model is in line with specifications suggested by the applied literature which empirically tests the validity of Gibrat's law (see Santarelli et al. (2006) for an exhaustive survey of empirical studies testing Gibrat's law). In this literature, firms' growth is modeled as a function of the initial size. Moreover, this baseline specification has been extended in order to account for several major control variables in level, such as productivity, export, external finance and R\&D activity as well as others. We refer to, within the very vast literature that investigates the growth of firms, Gibrat (1931); Penrose (1959); Evans (1987b,a); Doms et al. (1995); Del Monte and Papagni (2003); García-Manjón and Romero-Merino (2012).

${ }^{29}$ Correlation tables for the variables included in our specifications are available upon request.
} 
results in around a $32.2 \%$ increase in total revenues, a $7.5 \%$ increase in firms' growth and a $3.08 \%$ increase in profitability compared with not having both IP instruments, ${ }^{30}$ while having only trademarks or only patents have a lower effect.

In order to confer statistical precision to the results above, we verify the order of the coefficients for the IP binary variables performing a series of one-sided Wald-tests. A first set of tests (that we label H1_a, H1_b and H1_c in Table 3) reveals that, independently of the measure of performance considered, firms show higher performance if they own any IP right. We find that coefficients $\beta_{2}, \beta_{3}$ and $\beta_{4}$ are statistically larger than $\beta_{1}{ }^{31}$ Moreover, in a second set of tests (that we label H1_d and H1_e), we compare, on one hand, the magnitude of the coefficients of firms owning either only trademarks or patents (that is $\beta_{2}$, and $\beta_{3}$, respectively), and, on the other hand, the magnitude of the coefficients for the group of firms owning both patents and trademarks (that is $\beta_{4}$ ). Tests show that owning both IP rights has a higher impact than owning only one of the two IP instruments on all measures of performance (that is, $\beta_{4}>\beta_{2}$ and $\beta_{4}>\beta_{3}$ ). ${ }^{32}$ Note, however, that this result is not sufficient to conclude for the existence of complementarity effects on performance of the joint ownership of patents and trademarks.

In order to assess the potential complementarity in performance of these two IP rights, we rely on the theory of super-modularity (Milgrom and Roberts, 1990, 1995) according to which two activities are complementary if adding an one (e.g., patents) while the other is already being performed (e.g., trademarks) has a higher incremental effect on performance than adding this activity (e.g. patents) in isolation. Thus, we can assert that patents and trademarks display complementarity if the following inequality holds: ${ }^{33}$

$$
\beta_{4}-\beta_{3}>\beta_{2}-\beta_{1}
$$

The one-sided Wald test reported in Table 3 (H1_f), column 7, suggests that we can reject the null hypothesis of absence of complementarity between patents and trademarks only for profitability. Thus, there is statistical evidence that having both patents and trademarks is a superior IP strategy with respect to having only one of the two IP rights in order to increase firms' profitability. On the contrary, we do not find evidence of complementarity on revenues and growth (we refer to the tests reported in columns 1 and 4 , respectively).

It is not obvious to compare our results to the extant literature as, to our knowledge, we are the first to investigate the role of patents and trademarks on the entire population of firms, hence including also SMEs and micro ones. To the extent that such comparison is possible, our results are coherent with Zhou et al. (2016) who find that start-ups with both patents and trademarks obtain higher amount of venture capital funding than firms with only one of the two IP instruments. As for the combined effect of IP rights on firms' performance, our results on the absence of complementarity between patents and trademarks, when we consider revenues and growth as measures of performance, are in line with Llerena and Millot (2013). Considering firms' market value, the authors do not find any evidence of complementarity between patenting and trademarking activities on the

\footnotetext{
${ }^{30}$ The effect of having both IP on firms' performance is computed as follows: $\left(\beta_{4}-\beta_{1}\right) * 100$ when we consider total revenues and growth as measure of performance and $\left(\beta_{4}-\beta_{1}\right)$ when use profitability as proxy for performance.

${ }^{31}$ In Table 3 (columns 1,4 and 7) we reject the following null hypotheses: H0_a: $\beta_{2} \leq \beta_{1}$, H0_b: $\beta_{3} \leq \beta_{1}$ and H0_c: $\beta_{4} \leq \beta_{1}$.

${ }^{32}$ The null hypotheses are H0_d: $\beta_{4} \leq \beta_{2}$ and H0_e: $\beta_{4} \leq \beta_{3}$.

${ }^{33}$ The same condition can be expressed as follows: $\beta_{4}-\beta_{2}>\beta_{3}-\beta_{1}$.
} 


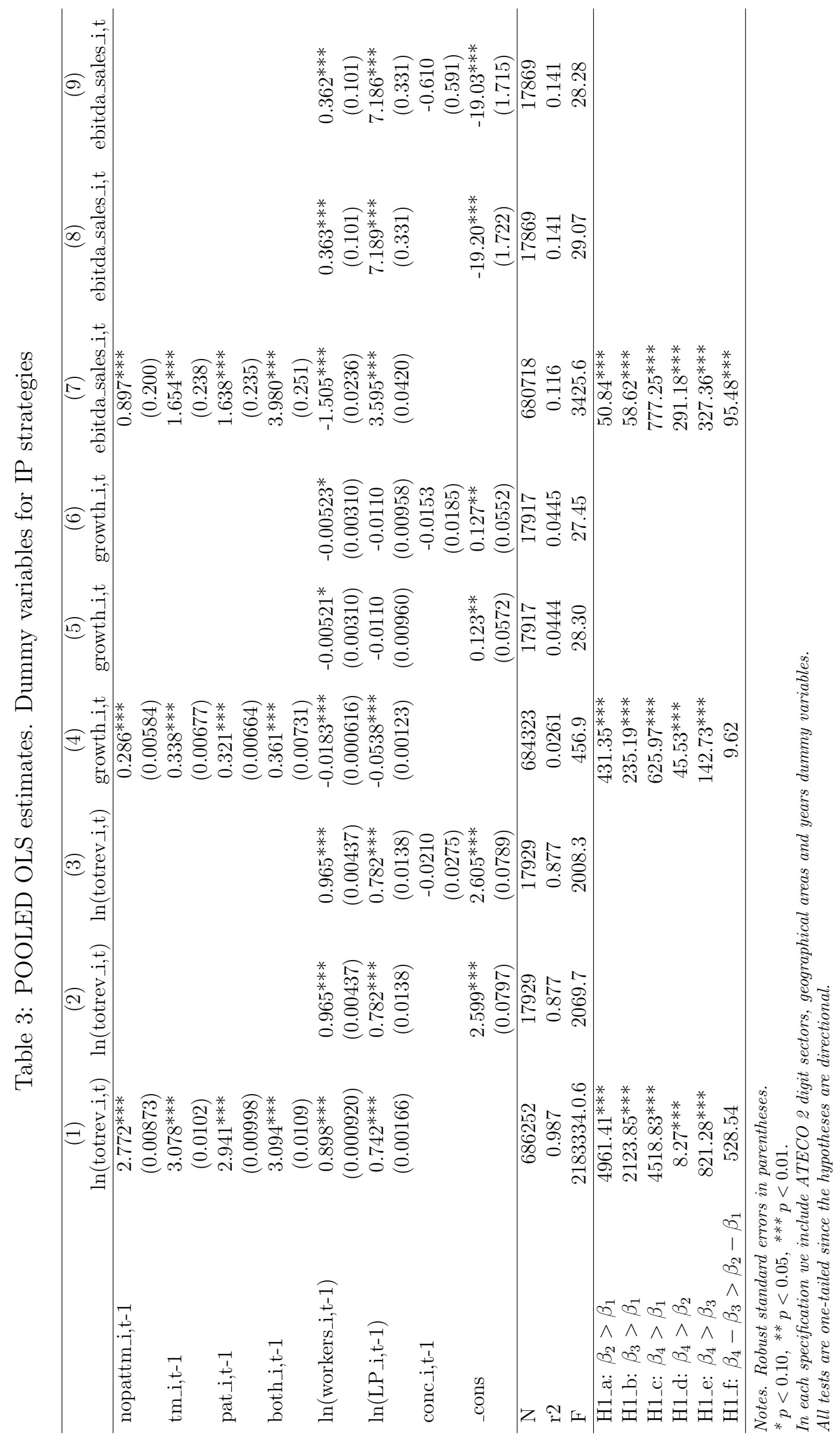


whole sample of publicly traded French firms. They find however that complementarity (substitutability) between IP strategies varies across sectors. In particular, they identify a positive combined effect for firms operating in chemical and pharmaceutical industries (they find a negative combined effect for firms operating in high-tech sectors). Also Dosso and Vezzani (2017) show that having both patents and trademarks implies higher firms' market value only for the automobile sector.

As far as the comparison between the two IP instruments is concerned, our estimates suggest that firms owning only trademarks show higher revenues and growth than firms with only patents. On the contrary, the impact of having only trademarks and the effect of having only patents do not differ when we consider profitability as proxy of firms' performance. $^{34}$ These results differ from Guzman and Stern (2015) and Castaldi and Dosso (2018) that focus on firms' growth as measure of performance. In particular, Guzman and Stern (2015) identify a higher effect of patents, compared to the effect of trademarks, on the start-up probability of achieving a meaningful growth outcome. Conversely, focusing on top R\&D investors, Castaldi and Dosso (2018) find only an indirect impact of trademarks on growth, with trademarks only mitigating the negative effect of patents on firm growth.

Focusing on the degree of concordance between the stock of patents and trademarks, as proxied by our proposed measure, parametric estimates do not suggest a significant relationship between the concordance of firms' IP rights and performance. Indeed, the degree of concordance never shows up as significant. We are cautious in interpreting this as suggesting the irrelevance of such measure, but rather consider this as the consequence of the very small number of Italian firms for which it is possible to compute the measure, that is, less than $2 \%$ of the complete sample. The same constraint was also affecting the analysis of the diversification patterns in knowledge (as proxied by patents) of Italian firms reported in Dosi et al. (2017). A certainly more appropriate context to assess its relevance would be provided by larger firms owning patents and trademarks, and also pursuing some - more or less deliberate - pattern of diversification in their technological knowledge.

In considering the other control variables of Table 3, we find that firms' size has a positive impact on firms' total revenues and a negative effect on growth. ${ }^{35}$ Focusing on profitability as measure of performance, size displays a negative and significant impact on firms' profitability when considering the whole sample (column 7), whereas it turns out as positive on the restricted sample (columns 8 and 9). This result might be explained by the higher size of firms with both IP rights. As shown by Crass et al. (2019), firms' profit margin falls as size increases and rises after a certain threshold. Focusing on productivity, our findings suggest a positive and significant impact on firms' total revenues and profitability, regardless of the sample considered (whole sample in columns 1 and 7 , and sub-sample of firms with both IP rights in columns 2 and 3 and in columns 8 and 9). When considering growth as dependent variable, productivity displays a negative and significant impact on the whole sample (column 4), whereas it turns out as not

\footnotetext{
${ }^{34}$ More precisely, the one-sided Wald-tests comparing the magnitude of coefficients $\beta_{2}$ and $\beta_{3}$ of Table 3 (not shown in the interest of space), support this evidence: in columns 1 and 4 , coefficients $\beta_{2}$ are bigger than coefficients $\beta_{3}$ (they are 3.078 and 2.941 in column 1 and 0.338 and 0.321 in column 4 , respectively); whereas, coefficients $\beta_{2}$ and $\beta_{3}$ in column 7 do not statistically differ (they are 1.654 and 1.638 , respectively). These tests are available upon request.

${ }^{35}$ The negative impact of initial firms' size on their growth is a common result in the literature, also known as violation of Gibrat's law (see e.g., Mazzucato and Parris, 2015; Castaldi and Dosso, 2018; Grazzi and Moschella, 2018).
} 
significant on the restricted one (columns 5 and 6). The lack of the (expected) positive relation between productivity and growth is not much surprising, at least for the Italian case, see Bottazzi et al. $(2005,2008)$.

\subsection{Accounting for patent and trademark counts}

While the previous regression analysis only considered dummy variables to account for patents and trademarks, in this section we extend our analysis to include the count of patents and trademarks. Although this certainly enables to extract a richer amount of information from IP data, it also comes at the cost of some possible bias. Indeed, as we are not able to identify patents belonging to a common family, for some firms we might over-estimate the true number of patents.

To account for patent and trademark counts, we modify our baseline specification as follows:

$$
\begin{gathered}
Y_{i, t}=c+\beta_{1} \ln \left(t m_{-} i, t-1\right)+\beta_{2} \ln \left(p a t \_i, t-1\right)+\beta_{3} \ln \left(p a t \_i, t-1\right) * \ln \left(t m_{-} i, t-1\right)+ \\
\beta_{4} \ln \left(\text { worker }_{i, t-1}\right)+\beta_{5} \ln \left(L P_{i, t-1}\right)+X_{i, t}^{\prime} \alpha+u_{i, t}
\end{gathered}
$$

where $\ln \left(t m_{-} i, t-1\right)$ and $\ln \left(p a t \_i, t-1\right)$ are the $(\log )$ number of patents and trademarks of each firm $i$ in each year $t-1$, respectively, and $\ln ($ pat_ $i, t-1) * \ln \left(t m_{-} i, t-1\right)$ is their interaction. To estimate the baseline and the extended specification, for both the whole sample and the restricted sample of firms with both IP rights, we build the number of patents and trademarks as the count of instruments in the stock of patents and trademarks plus one, this enables to include in the analysis also firms without IP instruments. In the extended specification we include the degree of concordance between IP rights, conc $_{i, t-1}$, its interaction with both the IP indicators $\left(\ln \left(t m_{-} i, t-1\right) * c_{0} c_{-} i, t-1\right.$ and $\left.\ln \left(p_{a t} \_i, t-1\right) * c_{0 n} \_i, t-1\right)$ and the triple interaction $\left(\ln \left(\right.\right.$ pat $\left._{-} i, t-1\right) * \ln \left(t m \_i, t-1\right) *$ conc $\left.c_{-}, t-1\right)$ in order to verify whether IP rights with higher concordance benefit the firm more.

Results in Table 4 confirm the positive impact of patents and trademarks on performance for the whole sample of firms (see columns 1, 4 and 7 in Table 4); indeed, independently of the measure considered, firms' performance increases as the number of patents and trademarks rises. Moreover, the interaction terms between patents and trademarks, reported in columns 1 and 4, suggest that having a larger patent (trademark) stock pay less, in terms of revenues and growth, for those firms which also own trademarks (patents). These results are in line with the evidence of a lack of complementarity between patenting and trademarking activity in enhancing firms' total revenues and growth already shown in Table 3. Further, when considering patent and trademark counts we do not find evidence of complementarity for profitability either.

Notice that since our concordance measure takes real values (between 0 and 1 ) only for firms owing both IP instruments, the specification that includes concordance can only be performed on the restricted sample, as it was the case when IP were measured by dummy variables (Table 3). Hence, in the regressions on the restricted sample one is estimating the impact of having an additional IP instruments among the subset of firms with both patents and trademarks. This and the restricted sample size contribute to explain the lack of significance or the change in sign with respect to full sample (Columns 1, 4 and 7 versus 3, 6 and 9 of Table 4). 


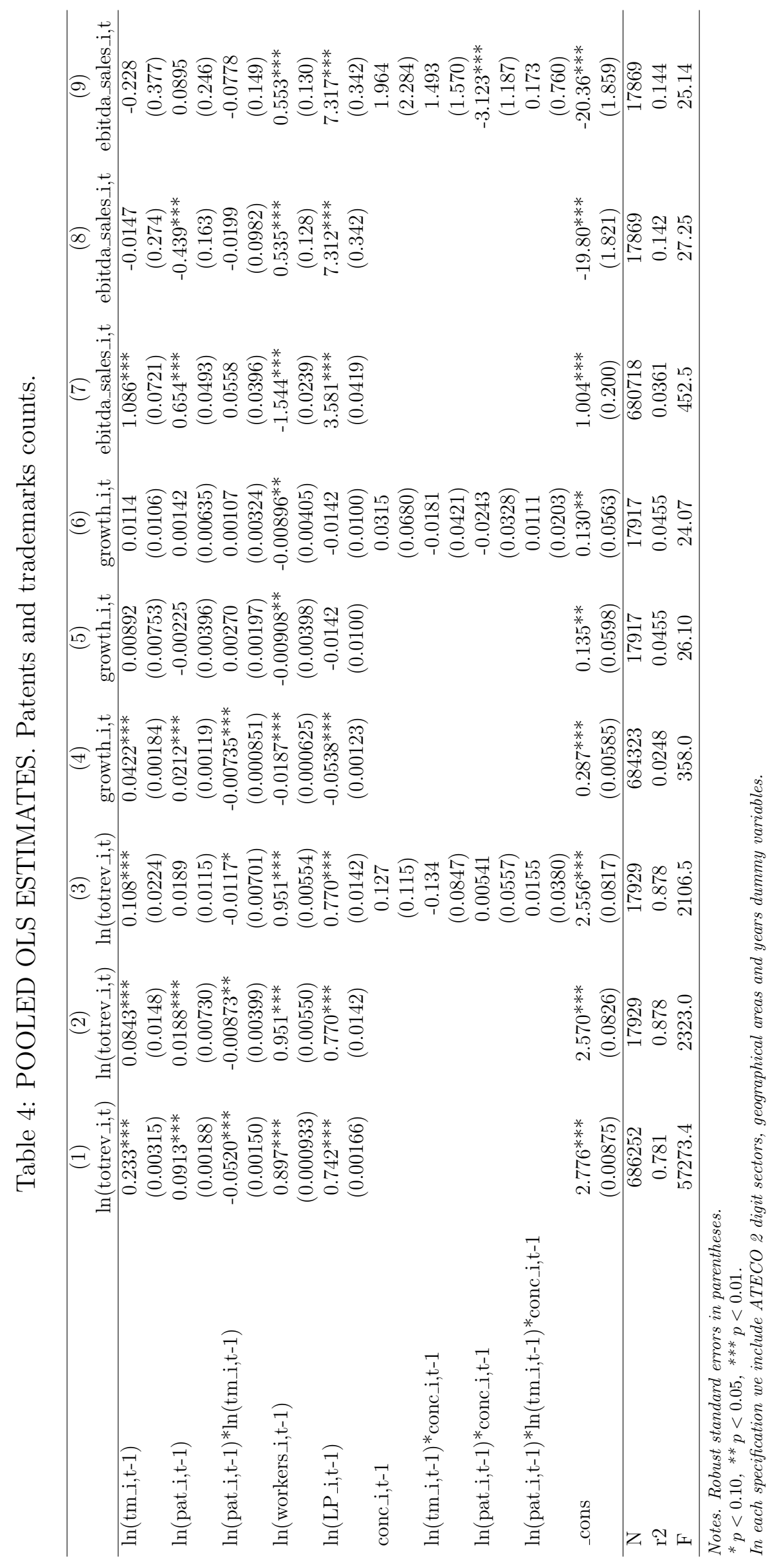


Table 5: Number of firms, trademarks and patents. SERVICE SECTOR

\begin{tabular}{|c|c|c|c|c|c|c|c|}
\hline Year & Firms & $\begin{array}{c}\text { Firms } \\
\text { with } \\
\text { tm }(\%) *\end{array}$ & $\begin{array}{c}\text { Firms } \\
\text { with } \\
\text { pat }(\%) *\end{array}$ & $\begin{array}{c}\text { Firms } \\
\text { with } \\
\text { tm and pat } \\
(\%) *\end{array}$ & $\begin{array}{c}\text { Firms } \\
\text { with } \\
\text { conc } c_{i, t}>0 \\
(\%) * *\end{array}$ & $\begin{array}{l}\text { Num } \\
\text { of } \\
\text { tm }\end{array}$ & $\begin{array}{l}\text { Num } \\
\text { of } \\
\text { pat }\end{array}$ \\
\hline 2006 & 476903 & $\begin{array}{r}2556 \\
(0.536)\end{array}$ & $\begin{array}{r}4157 \\
(0.872)\end{array}$ & $\begin{array}{r}310 \\
(0.065)\end{array}$ & $\begin{array}{r}244 \\
(78.710)\end{array}$ & 6396 & 21146 \\
\hline 2007 & 525751 & $\begin{array}{r}3094 \\
(0.588)\end{array}$ & $\begin{array}{r}4401 \\
(0.837)\end{array}$ & $\begin{array}{r}358 \\
(0.068)\end{array}$ & $\begin{array}{r}287 \\
(80.168)\end{array}$ & 7930 & 22586 \\
\hline 2008 & 575973 & $\begin{array}{r}3690 \\
(0.641)\end{array}$ & $\begin{array}{r}4606 \\
(0.800)\end{array}$ & $\begin{array}{r}406 \\
(0.070)\end{array}$ & $\begin{array}{r}325 \\
(80.049)\end{array}$ & 9752 & 24002 \\
\hline 2009 & 627089 & $\begin{array}{r}4378 \\
(0.698)\end{array}$ & $\begin{array}{r}4784 \\
(0.763)\end{array}$ & $\begin{array}{r}440 \\
(0.070)\end{array}$ & $\begin{array}{r}350 \\
(79.545)\end{array}$ & 11691 & 25129 \\
\hline 2010 & 684923 & $\begin{array}{r}5219 \\
(0.762)\end{array}$ & $\begin{array}{r}5035 \\
(0.735)\end{array}$ & $\begin{array}{r}522 \\
(0.076)\end{array}$ & $\begin{array}{r}414 \\
(79.310)\end{array}$ & 14017 & 26999 \\
\hline 2011 & 684039 & $\begin{array}{r}6044 \\
(0.884)\end{array}$ & $\begin{array}{r}5093 \\
(0.745)\end{array}$ & $\begin{array}{r}581 \\
(0.085)\end{array}$ & $\begin{array}{r}472 \\
(81.239)\end{array}$ & 16165 & 27853 \\
\hline 2012 & 673793 & $\begin{array}{r}6884 \\
(1.022)\end{array}$ & $\begin{array}{r}5007 \\
(0.743)\end{array}$ & $\begin{array}{r}635 \\
(0.094)\end{array}$ & $\begin{array}{r}515 \\
(81.102)\end{array}$ & 18430 & 27808 \\
\hline 2013 & 663075 & $\begin{array}{r}7640 \\
(1.152)\end{array}$ & $\begin{array}{r}4730 \\
(0.713)\end{array}$ & $\begin{array}{r}666 \\
(0.100)\end{array}$ & $\begin{array}{r}543 \\
(81.532)\end{array}$ & 20397 & 26300 \\
\hline 2014 & 644237 & $\begin{array}{r}7381 \\
(1.146)\end{array}$ & $\begin{array}{r}4354 \\
(0.676)\end{array}$ & $\begin{array}{r}625 \\
(0.097)\end{array}$ & $\begin{array}{r}509 \\
(81.440)\end{array}$ & 19741 & 24502 \\
\hline
\end{tabular}

Notes. We only consider firms operating in service sectors (we exclude firms operating in the following 2-digit ATECO 2007 code: 64, 65, 66 and 68) * In brackets, percentage of total firms.

** In brackets, as a percentage of firms with trademarks and patents.

\subsection{A focus on the service sector}

We have so far focused only on firms from manufacturing sectors, as out of doubt they account for the largest share of IP instruments in the economy. However, not only the service sector has become much more relevant in terms of GDP share, but the propensity to resort to IP has much increased as well. Hence, in this section we replicate our main analysis on the sub-sample of service firms.

Table 5 reports the distribution of trademarks and patents for firms in the service sector. In line with the literature, most service firms do not use any IP and the fraction of firms owning IP instruments is smaller than in the manufacturing sector. Taking as a reference the last year of observation (2014), 1.15\% of firms in own at least one trademark, around $0.68 \%$ at least one patent and only around $0.10 \%$ both IP instruments. Focusing on firms with both patents and trademarks, the degree of concordance, as defined in equation (2), is on average 0.18 , much similar to the manufacturing sector.

We estimate equation (3) on the sub-sample of service firms. Results, reported in Table 6, are much similar to manufacturing. Independently of the measure of performance considered, firms with any IP right display a superior performance vis à vis firms without IP rights (tests H1_a, H1_b and H1_c in Table 6); owning both IP rights has a higher impact than owning only one for all measures of performance considered (tests H1_d and H1_e in Table 6) and complementarity between patents and trademarks holds only with respect to profitability (tests $\mathrm{H} 1 \mathrm{f}$ in Table 6). Moreover, estimated coefficients (having only trademarks, only patents or both of them) are slightly higher in the service sector than in the manufacturing, independently of the measure of performance. Further, having both IP rights is associated to an increase in total revenues by $37.2 \%$ (by $32.2 \%$ for firms in manufacturing sector), growth by $9.6 \%$ (by $7.5 \%$ for firms in manufacturing sector) and profitability by $4,4 \%$ (by $3.08 \%$ for manufacturing firms). 


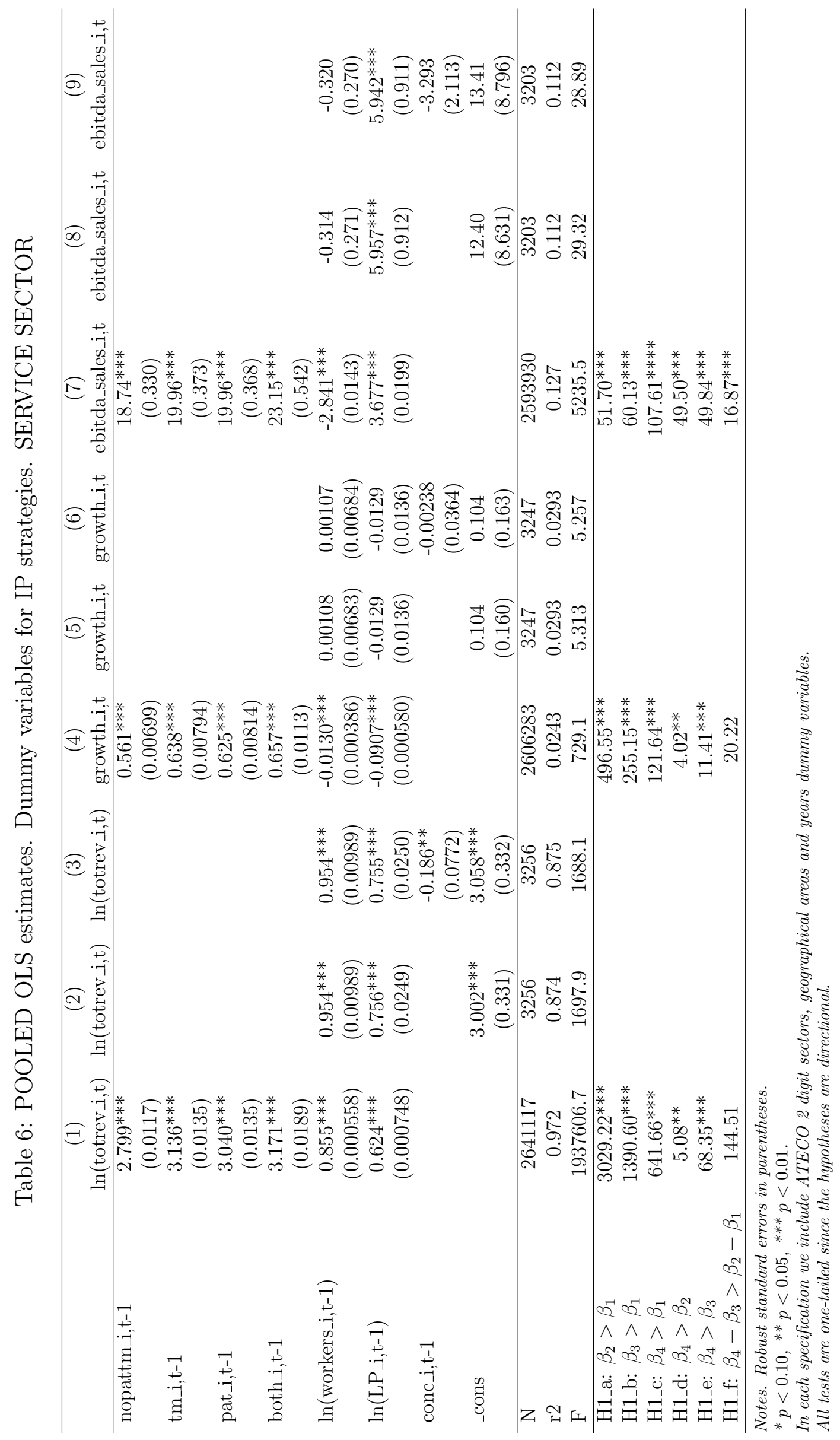


These results are quite in line with evidence from Hall and Sena (2017) and Greenhalgh and Rogers (2012). As far as the comparison between the two IP instruments is concerned, our estimates for the service sector are in line with those shown for manufacturing firms. The impact of owning only trademarks is larger for revenues and growth as compared to owning only patents.

In concluding, despite the different propensity to use IP rights for manufacturing and service firms (Tables 1 vs 5 ), the evidence from regression analysis suggests that the impact of IP strategies on firms' performance in both macro-sectors is significantly positive and similar.

\section{Conclusion}

We have analyzed the relationship between innovation activities and firms' performance in terms of revenues, growth and profitability.

Our contribution is threefold. First, differently from most empirical works, which focus on large and medium firms, on top corporate R\&D investors or on firms operating in hightech industries (see e.g., Greenhalgh and Rogers, 2006; Fang et al., 2011; Chang et al., 2012; Greenhalgh and Rogers, 2012; Dernis et al., 2015; Daiko et al., 2017; Dosso and Vezzani, 2017; Castaldi and Dosso, 2018), we have performed our analysis on IP taking into account the virtual universe of Italian limited liability manufacturing firms. Second, we have investigated whether there is a complementary or substitute relationship between the two instruments of IP. To the best of our knowledge, only few studies examine the combined impact of patents and trademarks on firms' performance (see e.g., Greenhalgh and Rogers, 2012; Sandner and Block, 2011; Dosso and Vezzani, 2017; Llerena and Millot, 2013; Jensen et al., 2008; Buddelmeyer et al., 2010; Helmers and Rogers, 2010; Wagner and Cockburn, 2010). Finally and completely novel, for firms owning both IP instruments, we have proposed a measure of concordance between a firm's stock of patents and trademarks, investigating the effect of this concordance on firms' performance.

Overall, our results indicate that IP rights exert a positive impact on firms' performance. When we focus on our preferred specification, having patent and trademark (irrespectively from their number) display a complementary effect when performance is measured by profitability

Although Italian firms do not represent the ideal testbed due to the very low share of firms with both patents and trademarks, we believe that the measure of concordance we propose can contribute to better understand how business firms engage in innovation activities and how this affects their performance. Establishing a linkage between patents and trademarks can shed some new light on the deliberate choice of the relative timing for the two activities. Do firms start with seeking protection for their technological innovation, or they rather decide to apply for a patent only when the introduction of a certain line of business, possibly protected by a trademark, has already proved to be succesfull? Further, the concordance measure or in other terms, the extent to which a given trademark (and the related product) is "backed up" by a patent, provides a more detailed perspective on the complementarity existing between IP instruments as it focuses on a specific product or line of business. Is the existence of patent-to-trademark linkage evidence of a "stronger" innovation, which is expected to generate higher profits?

We are of course aware of some limitations of our work. We remind the reader that for the construction of the measure of concordance we have extensively resorted to 
"Algorithmic Links with Probabilities (ALP)" which have themselves some limitations in terms of lack of precision. On a brighter side, also note that the public availability and use of such (and similar) ALP is also likely to generate some improvement over time. Second, and as apparent from this work even more relevant, the returns from employing the concordance measure largely depend on the characteristic of firms and in particular on their propensity to apply for patents and trademarks. Finally, and related to the latter point, we acknowledge that, focusing on patents and trademarks, we focus only on a subset of the instruments available to firms to appropriate the returns from formal and informal innovation activities (see among the others, Griliches, 1990; Dosi et al., 2006; Cohen et al., 2000).

\section{References}

AAKer, D. (2007): "Innovation: Brand it or lose it," California Management Review, $50,8-24$.

Angrist, J. D. And J.-S. Pischke (2008): Mostly harmless econometrics: An empiricist's companion, Princeton university press.

Belderbos, R., B. Cassiman, D. Faems, B. Leten, and B. V. Looy (2014): "Co-ownership of intellectual property: Exploring the value-appropriation and valuecreation implications of co-patenting with different partners," Research Policy, 43, 841 -852 .

Blind, K., J. Edler, R. Frietsch, And U. Schmoch (2006): "Motives to patent: Empirical evidence from Germany," Research Policy, 35, 655-672.

Block, J. H., C. O. Fisch, A. Hahn, And P. G. Sandner (2015): "Why do SMEs file trademarks? Insights from firms in innovative industries," Research Policy, 44, 1915-1930.

Bottazzi, G., M. Grazzi, And A. Secchi (2005): "Input Output Scaling Relations in Italian Manufacturing Firms," Physica A, 355, 95-102.

Bottazzi, G., A. Secchi, and F. Tamagni (2008): "Productivity, profitability and financial performance," Industrial and Corporate Change, 17, 711-751.

Bryce, D. J. And S. G. Winter (2009): "A General Interindustry Relatedness Index," Management Science, 55, 1570-1585.

Buddelmeyer, H., P. H. Jensen, And E. Webster (2010): "Innovation and the determinants of company survival," Oxford Economic Papers, 62, 261-285.

Cassiman, B. And R. Veugelers (2006): "In search of complementarity in innovation strategy: Internal R\&D and external knowledge acquisition," Management science, 52, 68-82.

Castaldi, C. And M. Dosso (2018): "From R\&D to market: using trademarks to capture the market capability of top R\&D investors," Tech. rep., Joint Research Centre (Seville site). 
Cefis, E. And L. Orsenigo (2001): "The persistence of innovative activities: A crosscountries and cross-sectors comparative analysis," Research Policy, 30, 1139-1158.

Chang, K.-C., D.-Z. Chen, And M.-H. Huang (2012): "The relationships between the patent performance and corporation performance," Journal of Informetrics, 6, 131139.

Cohen, W. M., R. R. Nelson, and J. P. Walsh (2000): "Protecting Their Intellectual Assets: Appropriability Conditions and Why U.S. Manufacturing Firms Patent (or Not)," Working Paper 7552, National Bureau of Economic Research.

Crass, D., D. Czarnitzki, And A. A. Toole (2019): "The dynamic relationship between investments in brand equity and firm profitability: evidence using trademark registrations," International Journal of the Economics of Business, 26, 157-176.

Crepon, B., E. Duguet, And J. Mairesse (1998): "Research, Innovation And Productivity: An Econometric Analysis At The Firm Level," Economics of Innovation and New Technology, 7, 115-158.

Czarnitzki, D. And K. KRAFT (2004): "Innovation indicators and corporate credit ratings: evidence from German firms," Economics Letters, 82, 377-384.

Daiko, T., H. Dernis, M. Dosso, P. Gkotsis, M. Squicciarini, A. Tuebke, and A. VezzAni (2017): "World Top R\&D Investors: Industrial Property Strategies in the Digital Economy," JRC Working Papers JRC107015, Joint Research Centre (Seville site).

De Rassenfosse, G., H. Dernis, and G. Boedt (2014): "An introduction to the Patstat database with example queries," Australian Economic Review, 47, 395-408.

De Rassenfosse, G. And A. B. Jaffe (2018): "Econometric evidence on the depreciation of innovations," European Economic Review, 101, 625-642.

Del Monte, A. And E. Papagni (2003): "R\&D and the growth of firms: empirical analysis of a panel of Italian firms," Research policy, 32, 1003-1014.

Dernis, H., M. Dosso, F. Hervas, V. Millot, M. Squicciarini, and A. Vezzani (2015): "World Corporate Top R\&D Investors: Innovation and IP bundles," JRC Working Papers JRC94932, Joint Research Centre (Seville site).

Dinlersoz, E., N. Goldschlag, A. Myers, and N. Zolas (2018): "An Anatomy of U.S. Firms Seeking Trademark Registration," in Measuring and Accounting for Innovation in the 21st Century, National Bureau of Economic Research, Inc, NBER Chapters.

Doms, M., T. Dunne, And M. J. Roberts (1995): "The role of technology use in the survival and growth of manufacturing plants," International Journal of Industrial Organization, 13, 523-542.

Dosi, G., M. Grazzi, And D. Moschella (2015): "Technology and costs in international competitiveness: from countries and sectors to firms," Research Policy, 44, $1795-1814$. 
(2017): "What do firms know? What do they produce? A new look at the relationship between patenting profiles and patterns of product diversification," Small Business Economics, 48, 413-429.

Dosi, G., L. Marengo, and C. Pasquali (2006): "How much should society fuel the greed of innovators?: On the relations between appropriability, opportunities and rates of innovation," Research Policy, 35, 1110-1121.

Dosso, M. And A. VezzAni (2017): "Firm market valuation and intellectual property assets," Tech. rep., Joint Research Centre (Seville site).

Evans, D. S. (1987a): "The Relationship between Firm Growth, Size, and Age: Estimates for 100 Manufacturing Industries," Journal of Industrial Economics, 35, 567-81.

(1987b): "Tests of Alternative Theories of Firm Growth," The Journal of Political Economy, 95, 657-674.

Fang, E., R. W. Palmatier, and R. Grewal (2011): "Effects of customer and innovation asset configuration strategies on firm performance," Journal of Marketing Research, 48, 587-602.

Fligner, M. And G. Policello (1981): "Robust rank procedures for the BehrensFisher problem," Journal of the American Statistical Association, 76, 141-206.

Flikkema, M., C. Castaldi, A.-P. De Man, and M. Seip (2019): "Trademarks' relatedness to product and service innovation: A branding strategy approach," Research Policy, 48, 1340-1353.

Flikkema, M., A.-P. De Man, and C. Castaldi (2014): "Are Trademark Counts a Valid Indicator of Innovation? Results of an In-Depth Study of New Benelux Trademarks Filed by SMEs," Industry and Innovation, 21, 310-331.

García-Manjón, J. V. And M. E. Romero-Merino (2012): "Research, development, and firm growth. Empirical evidence from European top R\&D spending firms," Research Policy, 41, 1084-1092.

Gibrat, R. (1931): Les inègalitès èconomiques, Librairie du Recuil Sirey, Paris.

Goldschlag, N., T. J. Lybbert, And N. J. Zolas (2016): "An Algorithmic Links with Probabilities Crosswalk for USPC and CPC Patent Classifications with an Application Towards Industrial Technology Composition," Working Papers 16-15, Center for Economic Studies, U.S. Census Bureau.

Graham, S. And D. Somaya (2004): "The Use of Patents, Copyrights, and Trademarks in Software: Evidence from Litigation," in Patents, Innovation and Economic Performance, ed. by D. Guellec, OECD.

Graham, S. J., C. Grim, T. Islam, A. C. Marco, and J. Miranda (2018): "Business dynamics of innovating firms: Linking U.S. patents with administrative data on workers and firms," Journal of Economics $\&$ Management Strategy, 27, 372-402.

Grazzi, M. AND D. Moschella (2018): "Small, young, and exporters: New evidence on the determinants of firm growth," Journal of Evolutionary Economics, 28, 125-152. 
Grazzi, M., C. Piccardo, and C. Vergari (2018): "Building a firm level dataset for the analyses of industrial dynamics and demography," Journal of Economic and Social Measurement, 43, 169-197.

Greenhalgh, C. And M. Rogers (2006): "Market Valuation of UK Intellectual Property: Manufacturing, Utility and Financial Services Firms," in The Management of Intellectual Property, Edward Elgar Publishing, Chapters, chap. 7.

(2012): "Trade Marks and Performance in Services and Manufacturing Firms: Evidence of Schumpeterian Competition Through Innovation," Australian Economic Review, 45, 50-76.

Griliches, Z. (1981): "Market value, R\&D, and patents," Economics Letters, 7, 183187.

(1990): "Patent Statistics as Economic Indicators: A Survey," Journal of Economic Literature, 28, 1661-1707.

Guzman, J. And S. Stern (2015): "Where is silicon valley?" Science, 347, 606-609.

HALl, B. H. (2000): "Innovation and market value," In: Barrell, R., Mason, G., OMahony, M. (Eds.), Productivity, Innovation and Economic Performance, 33, 13-33.

Hall, B. H., C. Helmers, M. Rogers, and V. Sena (2013): "The importance (or not) of patents to UK firms," Oxford Economic Papers, 65, 603-629.

Hall, B. H., F. Lotti, and J. Mairesse (2009): "Innovation and productivity in SMEs: empirical evidence for Italy," Small Business Economics, 33, 13-33.

Hall, B. H. AND V. SenA (2017): "Appropriability mechanisms, innovation, and productivity: evidence from the UK," Economics of Innovation and New Technology, $26,42-62$.

Helmers, C. And M. Rogers (2010): "Innovation and the survival of sew firms in the UK," Review of Industrial Organization, 36, 227-248.

Jensen, P. H., E. Webster, And H. Buddelmeyer (2008): "Innovation, technological conditions and new firm survival," Economic Record, 84, 434-448.

Leiponen, A. And J. Byma (2009): "If you cannot block, you better run: Small firms, cooperative innovation, and appropriation strategies," Research Policy, 38, 1478-1488.

Llerena, P. And V. Millot (2013): "Are Trade Marks and Patents Complementary or Substitute Protections for Innovation," Working Papers of BETA 2013-01, Bureau d'Economie Thèorique et Appliquèe, UDS, Strasbourg.

LotTi, F. AND G. MARIN (2013): "Matching of PATSTAT applications to AIDA firms: discussion of the methodology and results," Questioni di Economia e Finanza (Occasional Papers) 166, Bank of Italy, Economic Research and International Relations Area.

LybBert, T. J. And N. J. Zolas (2014): "Getting patents and economic data to speak to each other: an algorithmic links with probabilities approach for joint analyses of patenting and economic activity," Research Policy, 43, 530-542. 
Malerba, F. And L. Orsenigo (1999): "Technological entry, exit and survival: an empirical analysis of patent data," Research Policy, 28, 643-660.

Markides, C. C. And P. J. Williamson (1996): "Corporate Diversification And Organizational Structure: A Resource-Based View," Academy of Management Journal, 39, 340-367.

Mazzucato, M. and S. Parris (2015): "High-growth firms in changing competitive environments: the US pharmaceutical industry (1963 to 2002)," Small Business Economics, 44, 145-170.

Mendonça, S., T. S. Pereira, And M. M. Godinho (2004): "Trademarks as an indicator of innovation and industrial change," Research Policy, 33, 1385-1404.

Milgrom, P. And J. Roberts (1990): "The Economics of Modern Manufacturing: Technology, Strategy, and Organization," American Economic Review, 80, 511-28.

(1995): "Complementarities and fit: Strategy, structure, and organizational change in manufacturing," Journal of Accounting and Economics, 19, 179-208.

OHIM (2015): "Intellectual property rights and firm performance in Europe: an economic analysis," Tech. rep., Office for Harmonization in the Internal Market (OHIM).

Osservatorio Italiano Brevetti (2014): "Analisi del brevetto italiano. Dati sttistici e trends degli ultimi anni," Technical report, OIB.

Penrose, E. T. (1959): The theory of the growth of the firm, Oxford: Blackwell, 3rd ed.

Rogers, M., C. Helmers, and C. Greenhalgh (2007): "An Analysis of the Characteristics of Small and Medium Enterprises That Use Intellectual Property," Tech. rep., London: Report for the UK Intellectual Property Office.

SANDNER, P. G. AND J. Block (2011): "The market value of R\&D, patents, and trademarks," Research Policy, 40, 969-985.

Santarelli, E., L. Klomp, and A. R. Thurik (2006): "Gibrats Law: An overview of the empirical literature," in Entrepreneurship, growth, and innovation, Springer, $41-73$.

Schautschick, P. And C. Greenhalgh (2016): "Empirical studies of trade marksthe existing economic literature," Economics of Innovation and New Technology, 25, $358-390$.

Teece, D. J., R. Rumelt, G. Dosi, and S. Winter (1994): "Understanding corporate coherence: Theory and evidence," Journal of Economic Behavior $\&$ Organization, $23,1-30$.

Toivanen, O., P. Stoneman, and D. Bosworth (2002): "Innovation and the Market Value of UK Firms, 1989-1995," Oxford Bulletin of Economics and Statistics, 64, 39-61. 
WAGner, S. AND I. CockBurn (2010): "Patents and the survival of Internet-related IPOs," Research Policy, 39, 214-228.

Xu, B. And E. P. Chiang (2005): "Trade, patents and international technology diffusion," The Journal of International Trade \& Economic Development, 14, 115-135.

Zhou, H., P. G. Sandner, S. L. Martinelli, and J. H. Block (2016): "Patents, trademarks, and their complementarity in venture capital funding," Technovation, 47, $14-22$.

Zolas, N., T. J. Lybbert, and P. Bhattacharyya (2017): "An Algorithmic Links with Probabilities Concordance for Trademarks with an Application Towards Bilateral IP Flows," The World Economy, 40, 1184-1213. 


\section{Appendix: Example of concordance measure con- struction}

For illustrative purposes, consider the following example taken from our database for a firm (labeled 1) with four patents and nine trademarks in year 2006. As we can see from Table 7, the first patent (patent 1) has two IPC codes (A61 and H02), the second patent has one IPC code (C09) and both the third and fourth patents have one IPC code (A61). Thus, for firm 1 in year 2006 the set of 3-digit IPC codes includes the following three codes: A61, H02 and C09. Looking at the stock of trademarks, the first eight trademarks have the 2-digit NICE code 2, while the ninth trademark has the NICE code 35. Hence, for firm 1 in year 2006, the set of NICE codes includes the following two codes: 2 and 35 . So that $N_{L}^{1,2006}=3$ and $N_{K}^{1,2006}=2$. Based on the probabilistic algorithms by Lybbert and Zolas (2014) and Zolas et al. (2017), in Table 8 each IPC and NICE code is associated to the corresponding ISIC sectors (it can be more than one) with the relative probability weights. For example, we link the 3-digit IPC code A61 to the following ISIC codes 10, 20, 21, 32 and 36. For each ISIC code the algorithm provides a probability weight which identifies the likelihood of the linkage between the IPC code and each ISIC code. Similarly, for NICE code 2, we consider the following ISIC codes 2, 20, 25 and 41, each of them linked to a given probability weight.

In order to compute $\operatorname{conc}_{1,2006}$, we first determine the overlapping coefficient for each of the six pairs of IPC and NICE codes (A61-2, A61-35, C09-2, C09-35, H02-2 and H0235 ). For instance, overlap ${ }_{A 61-2}=0.0505$, with $N_{A 61,2}=8$, that is the number of ISIC codes associated to the pair $(\mathrm{A} 61,2) .{ }^{36}$ Hence, the degree of concordance between the two IP instruments is given by:

$$
\text { conc }_{1,2006}=(0.0505005+0+0.1203539+0+0+0) /(3 * 2)=0.028475733 .
$$

Table 7: Number of elements in the set of 3-digit IPC and 2-digit NICE codes.

\begin{tabular}{|c|c|c|c|c|c|}
\hline & \multirow{2}{*}{$\frac{\mathrm{ID}}{1}$} & \multirow{2}{*}{$\frac{\mathrm{TM}}{1}$} & \multirow{2}{*}{$\frac{\text { NICE }}{2}$} \\
\hline & & & & & \\
\hline ID & PAT & IPC & 1 & 2 & 2 \\
\hline 1 & 1 & A61 & 1 & 3 & 2 \\
\hline 1 & 1 & H02 & 1 & 4 & 2 \\
\hline 1 & 2 & C09 & 1 & 5 & 2 \\
\hline 1 & 3 & A61 & 1 & 6 & 2 \\
\hline 1 & 4 & A61 & 1 & 7 & 2 \\
\hline & & & 1 & 8 & 2 \\
\hline & & & 1 & 9 & 35 \\
\hline
\end{tabular}

\footnotetext{
${ }^{36} \mathrm{~A}$ common 2-digit ISIC code is identified only for the pairs of IPC and NICE codes A61-2 and C09-2. In particular, both the IPC code A61 and the NICE code 2 are linked to the ISIC code 20; while, both the IPC code C09 and the NICE code 2 are linked to the ISIC code 20. Thus, the overlapping coefficients are different from zero only for these pairs on IPC and NICE codes (0. 0505005 and 0.1203539 for pairs A61-2 and C09-2, respectively).
} 
Table 8: Moving from IPC and NICE to ISIC codes.

\begin{tabular}{ccc}
\hline IPC & ISIC & $\mathrm{P}_{I P C}($ ISIC $)$ \\
\hline $\mathrm{A} 61$ & 10 & 0.0361579 \\
$\mathrm{~A} 61$ & 20 & 0.0505005 \\
$\mathrm{~A} 61$ & 21 & 0.8616829 \\
$\mathrm{~A} 61$ & 32 & 0.0302412 \\
$\mathrm{~A} 61$ & 36 & 0.0214176 \\
$\mathrm{C} 09$ & 20 & 0.9659607 \\
$\mathrm{C} 09$ & 23 & 0.0340393 \\
$\mathrm{H} 02$ & 24 & 0.0637551 \\
$\mathrm{H} 02$ & 26 & 0.0888389 \\
$\mathrm{H} 02$ & 27 & 0.8212442 \\
$\mathrm{H} 02$ & 28 & 0.0261618 \\
\hline
\end{tabular}

\begin{tabular}{ccc}
\hline NICE & ISIC & $\mathrm{P}_{\text {NICE }}$ (ISIC) \\
\hline 2 & 2 & 0.0491944 \\
2 & 20 & 0.1203539 \\
2 & 25 & 0.8065651 \\
2 & 41 & 0.0238867 \\
35 & 46 & 0.1524157 \\
35 & 63 & 0.0744019 \\
35 & 69 & 0.0240318 \\
35 & 70 & 0.0710176 \\
35 & 73 & 0.4864157 \\
35 & 78 & 0.0490504 \\
35 & 82 & 0.0307544 \\
35 & 90 & 0.0424586 \\
35 & 94 & 0.0694538 \\
\hline
\end{tabular}

